\title{
Growing Wealth Gaps in Education
}

\author{
Fabian T. Pfeffer* \\ University of Michigan \\ Forthcoming in Demography
}

\begin{abstract}
Prior research on trends in educational inequality has focused chiefly on changing gaps in educational attainment by family income or parental occupation. In contrast, this contribution provides the first assessment of trends in educational attainment by family wealth and suggests that we should be at least as much concerned about growing wealth gaps in education. Despite overall growth in educational attainment and some signs of decreasing wealth gaps in high school attainment and college access, I find a large and rapidly increasing wealth gap in college attainment between cohorts born in the 1970 and 1980s, respectively. This growing wealth gap in higher educational attainment co-occurred with a rise in inequality in children's wealth backgrounds, though the analyses also suggest that the latter does not fully account for the former. Nevertheless, the results reported here raise concerns about the distribution of educational opportunity among today's children who grow up in a context of particularly extreme wealth inequality.
\end{abstract}

*This work has been supported by an award from the Spencer Foundation (grant \#201300139) and the Russell Sage Foundation. The collection of data used in this study was partly supported by the National Institutes of Health (grant \#R01HD069609) and the National Science Foundation (grant \#1157698). Any opinions expressed are those of the author alone and should not be construed as representing the opinions of the funding agencies. Earlier versions of this paper were presented at meetings of the Population Association of America, the American Sociological Association, and the Research Committee on Social Inequality and Mobility (RC28). I think Sheldon Danziger, Thomas DiPrete, Alexandra Killewald, and Robert Schoeni for helpful comments on an earlier version. A replication package containing the data and code used for this paper is available through the PSID Public Data Extract Repository at https://www.openicpsr.org/openicpsr/psid (\#101105). Please direct all correspondence to Fabian T. Pfeffer, University of Michigan, 4213 LSA Building, 500 South State Street, Ann Arbor, Michigan 48109, fpfeffer@umich.edu. 


\section{INTRODUCTION}

Family wealth - measured as the net value of all financial and real assets a family owns - is much more unequally distributed than other indicators of families' economic wellbeing (Keister 2000). Research has documented that this already large inequality in family wealth in the United States has been increasing substantially over the last decades (Wolff 1995; Keister and Moller 2000; Piketty and Zucman 2014; Saez and Zucman 2014) and particularly strongly since the Great Recession (Pfeffer et al. 2013; Wolff 2016). One concern about growing wealth inequality is that it may also increase the rigidity of U.S. society, in particular by contributing to inequalities in educational opportunity. In fact, a growing body of research suggests that parental wealth plays an important role in the educational attainment of children in the United States and elsewhere (Conley 2001; Morgan and Kim 2006; Belley and Lochner 2007; Pfeffer 2011; Haellsten and Pfeffer 2017). Over the last decades, family wealth may have become even more important to support direct investments in educational opportunity - in the form of good neighborhoods, secondary schools, and colleges - and to insure against the risks entailed in these investments, for instance, when families rely on student loans to finance costly college careers. As families drift apart in their wealth holdings, so may their ability to use wealth for investment and insurance. Yet, to date, there is no empirical evidence on whether and to what extent wealth gaps in education have grown.

This contribution provides the first empirical assessment of trends in wealth inequality in educational outcomes based on newly available data from the Panel Study of Income Dynamics (PSID). It also documents the extent to which these changes in wealth gaps in education can be accounted for solely by changes in the distribution of family wealth. Together, these analyses thus also speak to concerns about the potential long-term implications of the most recent and sharp increase in family wealth inequality for the future distribution of educational outcomes.

I begin by reviewing prior research on cohort trends in educational inequality. In the next 
section, I argue that this prior evidence, which is restricted to other socio-economic indicators of family background, does not allow inferences about trends in wealth gaps: Family wealth is empirically and conceptually distinct from more commonly used socio-economic indicators and it contributes unique predictive power to assessments of children's educational outcomes. After describing the data, measures, and methods, I estimate the association between family wealth and children's educational attainment, unconditional and conditional on other socioeconomic characteristics of families, and document how wealth-education associations have changed over recent cohorts. Finally, I apply a decomposition analysis to estimate the extent to which these changes can be accounted for by changes in the distribution of family wealth. Knowing whether trends in wealth inequality account for trends in children's educational outcomes is important as the wealth distribution has continued to grow even more unequal among today's children.

\section{BACKGROUND AND MOTIVATION}

\section{Prior research on trends in educational inequality}

The study of cohort trends in socio-economic inequality in education has been an active area of empirical investigation for several decades (e.g. Treiman 1970; Mare 1981; Shavit and Blossfeld 1993; Harding et al. 2004). Research in this area investigates the changing relationship between educational attainment and a variety of indicators of socio-economic background. One set of contributions draws on occupation-based measures of parents' social class and documents remarkably stable class gaps in children's educational outcomes in the U.S. over much of the 20th and early 21st century (Hout et al. 1993; Roksa et al. 2007; Pfeffer and Hertel 2015). Other research tracks the association between children's and their parents' highest educational status and also finds largely stable levels of educational inequality tied to parental education (Mare 1981; Hout and Dohan 1996; Pfeffer 2008; Hout and Janus 2011; Bloome and Western 2011) as well as some signs of growing gaps for more recent cohorts 
(Buchmann and DiPrete 2006; Hertz et al. 2007; Roksa et al. 2007; Pfeffer and Hertel 2015). The most notable and widely discussed changes in educational inequality, however, have been found in relation to family income: Reardon (2011) documents that the gaps in educational achievement (i.e. test scores) between children from high-income and low-income families has been growing steadily for at least fifty years. Similarly, income gaps in higher education have also grown: Belley and Lochner (2007) observe substantial increases in income inequality in college attendance, comparing a cohort born in the early 1960s to a cohort born in the early 1980s. Bailey and Dynarski (2011) show that these trends extend to growing income gaps in college graduation among the same cohorts. While income gaps in college attendance have held stable for more recent cohorts (Chetty et al. 2014; Ziol-Guest and Lee 2016), income gaps in college attainment have continued to increase (Duncan et al. 2017; Ziol-Guest and Lee 2016). The most recent estimates indicate that the difference in college graduation between children from the bottom and the top family income quintile approaches 50 percentage points (Ziol-Guest and Lee 2016).

Overall, then, cohort changes in the distribution of educational attainment are more pronounced in relation to parental income than in relation to parental education or parental occupations. It may thus be tempting to infer that rising income gaps in education should also manifest in rising gaps related to family wealth; after all both are monetary dimensions of families' socio-economic standing. However, as I will argue next, such direct inference is neither empirically nor conceptually valid - wealth is distinct from income, its association with education is distinct, and trends in that association may thus be distinct, too.

\section{Wealth as an independent predictor of educational attainment}

Some see conceptually few differences between wealth and income. In a strict model of neoclassical economics - that is, a world with perfect credit markets and in which wealth is accumulated from income rather than intergenerational transfers - wealth merely reflects different consumption patterns (see, e.g., the Haig-Simons income concept): Depending on 
their time preferences and levels of risk aversion, some individuals prefer to consume now while others do not and instead accumulate wealth. Over the entire life-course, income and wealth are thus seen as conceptually equivalent. This understanding of wealth does not correspond well to empirical findings: Prior research on wealth has often pointed out that correlations between wealth and other background characteristics are far from perfect and that especially the correlation between income and wealth is lower than one may expect (Oliver and Shapiro 1997; Keister and Moller 2000). In the analytic sample used for this analysis the correlation between family net worth ranks and 5-year average of family income ranks is .70 , which is higher than the correlation of .50 mentioned in the prior literature (Keister and Moller 2000; but see also Killewald et al. 2017), but not high enough to discard one measure in favor of the other. One reason why wealth is not empirically equivalent to life-time income is the importance of intergenerational transfers, which account for more than half of all wealth in the U.S. (Gale and Scholz 1994). Conversely, Brady et al. (forthcoming) have shown that wealth captures only a quarter to a third of fully observed life-time income in the United States.

Prior wealth research shares this insight and has found that, conditional on income and other observable characteristics, family wealth is related to a range of important outcomes, including children's education (for an overview see also Killewald et al. 2017). Researchers have documented independent associations between family net worth and children's early test scores (Orr 2003; Yeung and Conley 2008), their total years of schooling completed (Axinn et al. 1997; Conley 2001; Pfeffer 2011), as well as each level of educational attainment (Conley 1999, 2001; Morgan and Kim 2006; Belley and Lochner 2007; Haveman and Wilson 2007). A related strand of research has focused on housing wealth as the largest wealth component in most families' asset portfolios. For instance, home ownership has been shown to affect both early cognitive development of children and later college access (e.g. Haurin et al. 2002; Hauser 1993). Lovenheim (2011) found that exogenous shocks to home values 
substantially increase children's college going rates. ${ }^{1}$ In this contribution, I therefore also separately document gaps in educational attainment as they relate to housing wealth as a select and important aspect of families' overall wealth position.

\section{Why wealth gaps in education may be on the rise}

Prior research has also offered a range of potential explanations for the independent role of wealth in the educational attainment process. Families may draw on their wealth to invest in their children, in particular through the purchase of educationally valuable goods (e.g. tutoring and test preparation, Buchmann et al. 2010). Moreover, family wealth may facilitate access to certain types of education: In the form of housing wealth (home values), it provides access to high-quality public schools that - thanks to the reliance of public school budgets on local property taxes - are equipped with more resources than those in less wealthy neighborhoods. Also, wealth may help reduce credit constraints for college access and persistence. Lastly, family wealth may serve an insurance function by providing important "real and psychological safety nets" (Shapiro 2004) against the risks inherent in human capital investment decisions. For instance, one risk entailed in going to college is the possibility of failing to attain a terminal degree that may be necessary to pay off accumulated student debt. Family wealth may insure against that risk as it provides the option to meet debt obligations via intergenerational transfers. The lack of family wealth, on the other hand, increases the risk of realizing these sunk costs and may therefore prevent children from enrolling in college in the first place or from taking on more student debt to remain there (Pfeffer and Haellsten 2012).

Each of these pathways through which family wealth may translate into educational opportunity can be hypothesized to have increased in importance over recent decades. First,

\footnotetext{
${ }^{1}$ Although it is not the aim of this contribution to assess whether the association between family wealth and children's education is causal, it is worth nothing that Lovenheim's evidence on the causal relationship between housing wealth and college entry is an important advance in the literature, especially in the context of continuing debates about the causal influences of family income (see e.g. Mayer 1997; Cameron and Taber 2004).
} 
Kornrich and Furstenberg (2012) document a steep rise in the amount of money parents spend on their children, in particular for their education. Most of that increase occurred between the mid 1970s and mid 1990s, which corresponds to the time period in which the children analyzed here grow up. While prior research has shown these transfers to be related to families' income (McGarry and Schoeni 1995; Schoeni and Ross 2005; Kaushal et al. 2011), Rauscher (2016) reveals that parental transfers are also and increasingly closely tied to parental wealth: The size of transfers for children's schooling by parents in the upper half of the wealth distribution exceeds those by parents in the lower half more than sevenfold.

Second, the economic segregation of neighborhoods has increased since the 1970s (Reardon and Bischoff 2011; Taylor and Fry 2012) and, alongside of it, so has the economic segregation of schools (Owens et al. 2016). Although these trends have only been empirically established using measures of income, similar trends may apply to wealth: For instance, Owens et al (2016) have shown that the increasing income segregation of schools is primarily driven by those in the top 10 percent of the income distribution, that is, those most likely to hold wealth (Keister and Moller 2000: p. 225ff; Oliver and Shapiro 2006: p. 76ff.). Furthermore, the link between rising inequality and segregation that has been established for income (Watson 2009; Owens 2016) may be even stronger for wealth as families' selection into housing markets directly determines both residential segregation and wealth inequality. In fact, as shown by McCabe (2016), home owners often engage in decisively exclusionary politics to maximize the financial investment in their homes. Finally, since property-tax based school financing provides a tight link between school inputs and housing wealth, the extent to which residential segregation translates into differences in resources available to local schools should depend more on a neighborhood's wealth distribution than its income distribution. In sum, then, it seems reasonable to expect that growing wealth inequality has increased inequality in school contexts and resources, though this hypothesis urgently awaits empirical confirmation.

Third, one may expect credit constraints for college access and persistence to have in- 
creased as the cost to attend has risen dramatically over recent decades. The average, inflation-adjusted cost for in-state tuition and board at four-year colleges is more than 2.5 times higher today than what it was in 1980 (College Board 2015). Without a commensurate increase in financial aid, ${ }^{2}$ these rising costs may have increased the importance of family wealth in alleviating students' credit constraints. Furthermore, this trend may have been compounded by changes in educational policy as the 1992 Higher Education Act excluded home ownership from the calculation of financial need and thereby increased the total amount of financing available to children from families with high home equity (Dynarski 2002).

Fourth, with increasing costs of attendance come increasing costs of failure: The prospect of leaving college in student debt but without a degree to make up for it may have increased family wealth's insurance function. This function may also have become more consequential as job market insecurity and levels of life course risks (or the perception therefore) have increased while some public insurance schemes have deteriorated (Hacker 2007).

So far, I have offered reasons to expect a growing importance of family wealth in determining educational success in response to specific social and institutional changes, namely the heightened private investment in children, the increased economic segregation of neighborhood and schools, the rising costs of college attendance, and increasing insecurities facing children and young adults as they embark on their educational and labor market careers. However, in addition to family wealth becoming a more consequential resource for successful educational trajectories, increasing inequality in wealth alone may also translate into growing wealth gaps in education. That is, even if the way in which wealth is tied to educational success does not change, if children move further apart from each other in terms of their family wealth they may also do so in terms of their educational outcomes: For example, as the amounts of wealth available to families diverge, so should the amounts of spending on investments in children (assuming a positive elasticity of consumption). Furthermore, such

\footnotetext{
${ }^{2}$ The net cost to attend college (i.e. tuition/fees/board minus all financial aid and tax credits) has risen less steeply than sticker prices but still profoundly: In the 25 years between 1990 and 2015, the average net cost of attendance at public four-year colleges rose by 83 percent (while the sticker price rose by 110 percent) and at private four-year colleges by 39 percent (sticker price by 78 percent) (College Board 2015).
} 
divergence can have multiplicative effects if increased investment at the top devalues investment at the bottom: For instance, concentration of advantage in wealthy neighborhoods and schools or concentration of investments in test preparation may skew the competition for access to selective colleges to an extent that families of lower wealth are effectively priced out of the competition, creating a winner-take-all market (Frank and Cook 1996). As I will document below, the distribution of wealth has indeed grown substantially more unequal among the children studied here, including but not limited to the period of the Great Recession (Pfeffer et al. 2013; for a detailed consideration of the potential implications of the Great Recession for the analyses reported here see Appendix B). I will assess to what extent this growth in wealth inequality accounts for changing wealth gaps in educational outcomes using decomposition analyses.

Finally, like changes in educational inequality in general, trends in wealth gaps will also depend on the supply of education, namely the stage and pace of educational expansion. First, inequality at a given level of education, such as high school attainment, necessarily decreases when expansion at that level continues in spite of saturation (i.e. close to 100 percent completion rates) among the wealthy (Raftery and Hout 1993). This condition appears to be met for the cohorts analyzed here: High school graduation rates among the wealthiest are arguably saturated (as will be shown below), but national high school graduation rates have inched up another five percentage points over the period studied (NCES 2016a, Table 1). Second, trends in inequality at a given level, such as college access, can decrease or remain stable when that level expands faster than eligibility for it does (Arum et al. 2007). These conditions are also met over the observation period as enrollment in degree-granting post-secondary institutions increased by more than a third, even when excluding the growth in enrollment by foreign students (NCES 2016b, Tables 303.70 and 310.20). In sum, both at the level of high school graduation and college access, supply-side factors may serve to counter or even outweigh the factors described earlier. 


\section{Data, Measures, Method}

The Panel Study of Income Dynamics (PSID 2017) continually collects a rich set of longitudinally consistent indicators of the socio-economic position of families, which greatly facilitates the type of over-time comparisons reported here. It also collects information on the children born into a panel household and tracks them as they move out to establish their own households, making possible the assessment of their final educational outcomes. As the PSID has been collecting detailed wealth information since 1984, it is the only nationally representative survey that contains information on both family wealth and children's educational outcomes for a sufficiently wide range of different birth cohorts.

The analytic sample for this study consists of children who lived in PSID households at age 10-14 in the first four waves in which family wealth was measured $(1984,1989,1994$, 1999), which amounts to birth cohorts 1970 through 1989. That is, all trends in educational attainment assessed here occur over the span of the relatively brief time interval of just two decades. I will return to a discussion of potential longer-term trends in the final section of this paper. To track cohort changes in educational attainment, I compare children born in the 1970s to children born in the 1980s and assess whether, at age $20(\mathrm{~N}=2,334$ and $\mathrm{N}=2,691$, respectively), they have graduated from high school and whether they have gained any college experience, as well as whether, by age $25(\mathrm{~N}=1,799$ and $\mathrm{N}=2,545)$, they have completed a bachelor's degree. ${ }^{3}$ The indicators of educational attainment available here only record whether a year of college has been completed and therefore do not allow the separate identification of students who enter college but drop out within the first year, nor do they allow distinguishing between different types of colleges attended.

Information on children's educational attainment is provided either by the children them-

\footnotetext{
${ }^{3}$ Since 1997 the PSID is a bi-annual survey, so I assess educational attainment at ages 20/25 if surveyed in that year but at adjacent ages (older if available) if not. Online Appendix S.1 provides an overview of the different measurement years for each birth cohort. It also describes in detail how birth cohorts were differently affected by the 1997 PSID sample reduction but that the conclusions presented here do not appear to be substantially influenced by it.
} 
selves if they have already established their own households - very few of them have done so by age 20 - or by the origin household's respondent, typically a parent. The regression models described below control for the source of information on educational attainment.

The PSID collects wealth information based on a series of detailed questions on the ownership of assets and their value, covering home values, savings, stocks, many other financial assets, real estate, business assets, vehicles, mortgages, and other types of debt. As the main measure of wealth, this study uses total family net worth, which sums the value of all asset types minus debts. ${ }^{4}$ In addition, I draw on the value of respondents' owner-occupied homes as a much simpler proxy indicator. If home values, as one of the major components of most households' wealth portfolio, approximate the wealth-education associations studied here well, data limitations that so far have hampered the widespread inclusion of wealth in analyses of educational attainment would be greatly relaxed: Information on home values - without even considering remaining mortgage principals - is faster and easier to collect than full-fledged asset modules, feasibly even through linkage of existing surveys to external data, such as historical Censuses or commercial real-estate data. Wealth gaps based on other proxy measures, namely home equity and financial wealth, are also discussed briefly and reported in Appendix A.2.

The PSID wealth measures have been shown to have high validity though they do not capture the very top (2-3 percent) of the wealth distribution well (Juster et al. 1999; Pfeffer et al. 2016). Since this study focuses on population associations between wealth and education rather than the educational pathways of children of a small wealth elite (for the latter

\footnotetext{
${ }^{4}$ Here, family wealth is defined as the characteristic of the household in which the child resides at age 1014, irrespective of the household's structure, in an attempt to best capture the economic conditions in which the child grows up. A different measurement approach would instead link children to the wealth reports of their parents, which, for non-intact families, can provide additional information on the wealth of non-resident parents (this alternative approach could also be applied in studies focused on family income but typically is not). However, this information is only available for a selective set of cases where the non-resident parent continues to be interviewed as a PSID respondent. In addition, it is debatable whether and how a nonresident parent's wealth should be taken into account: Including the wealth of a "truly absent" parent may induce as much measurement error as failing to include the wealth of a non-resident parent with continued parenting commitments (undivided by new parenting commitments to step-children). In other work on the intergenerational effects of wealth (AUTHOR forthcoming), I have tested the sensitivity of results to these two distinct measurement approaches and concluded that they do not yield substantively different findings.
} 
see, e.g., Khan 2012), this shortcoming is less problematic and likely results in a conservative estimate of the educational advantages among the top wealth group assessed here. In fact, the specification of wealth gaps reported here draws on wealth quintiles to capture nonlinearities in intergenerational associations throughout the distribution but not necessarily the very top. Quintiles are drawn within each cohort and based on the weighted analytic sample; analyses based on unweighted quintiles yield similar results (see Online Appendix S.2).

This study also uses a comprehensive set of indicators of the socio-economic position of families besides family wealth. As a measure of permanent income, I use total household income averaged across five income years (centered on the year at which wealth is measured; specified as weighted quintiles). Educational background is measured as the highest degree attained by either the household head or partner. Occupational background is measured as the highest socio-economic index score (SEI) of either head's or partner's main occupation. Further controls for demographic characteristics include household size, the number of children in the household, whether the household head is married, mother's age, individuals' sex, and the source of information on their educational outcomes (self-reported or not). Each of these yearly measures is drawn from the same survey wave as the wealth measure (1984, 1989, 1994, 1999). The main predictor studied here, family wealth, is provided in imputed form by the PSID, and so is family income; few missing values on all remaining predictors are imputed using Stata's mi procedures. A small share of cases (less than 1 percent) with imputed values on the dependent variable are dropped (von Hippel 2007). Descriptive statistics for all variables included in this analysis are reported in Appendix A.1. All dollar values are inflation adjusted to 2015.

Wealth gaps in high school attainment, college access, and bachelor's degree attainment are estimated via logistic regressions. To allow a more direct assessment of wealth gaps in college persistence, I also estimate models for bachelor's degree attainment conditional on college access. I begin by describing observed rates of educational attainment by family 
wealth quintiles. Next, I estimate adjusted rates based on models including the control variables mentioned above. I report predictive margins and, for the cohort comparison, discrete changes based on average marginal effects (see Hanmer and Ozan Kalkan 2013) using Stata's margin commands (Long and Freese 2014). ${ }^{5}$ The decomposition approach used to estimate the extent to which changes in the wealth distribution account for trends in wealth gaps in education is targeted at explaining a specific trend revealed in the preceding analyses and will therefore be described later. The regression results reported draw on longitudinal, individual weights that account for selective attrition, though unweighted analyses yield substantively equivalent results (see Online Appendix S.2). Reported standard errors are robust and adjusted for clustering by PSID lineages (original PSID households), adjusting for the presence of not only siblings but also cousins.

\section{FINDINGS}

\section{Wealth gaps in educational attainment}

I begin by reporting differences in educational attainment by family wealth. Figure 1 displays average rates of high school attainment, college access, and college completion across wealth quintiles (with 95 percent confidence intervals), where wealth is measured as (a) net worth or (b) home values (see also Table A.2). The wealth gradient in educational attainment is steep: Comparing the educational outcomes of children from the lowest net worth quintile to those from the highest quintile reveals a difference of 18.3 percentage points in high school graduation rates (72.8 versus 91.1 percent), of 32.1 percentage points for college access (21.4 versus 53.5 percent) and a 44.6 percentage point difference for college graduation (9.1 versus 53.7 percent). The increase in rates across net worth quintiles is relatively linear for all levels of educational attainment, though we can observe a somewhat steeper increase in high school graduation rates in the bottom half of the distribution and a steeper increase in college

\footnotetext{
${ }^{5}$ Stability analyses based on linear probability models are presented in Online Appendix S.3
} 
graduation in the top half of the distribution. Furthermore, while wealth gaps between the highest and the second highest net worth quintile are relatively low for college access (53.5 versus 48.9 percent), they are more pronounced for college graduation (53.7 versus 36.4 percent). In fact, among children from the highest net worth quintile college access rates at age 20 and college graduation rates at age 25 are basically the same, suggesting a much higher level of college persistence among the top quintile (see also last column of Table A.2).

Figure 1: Educational Rates by Wealth Background

(a)

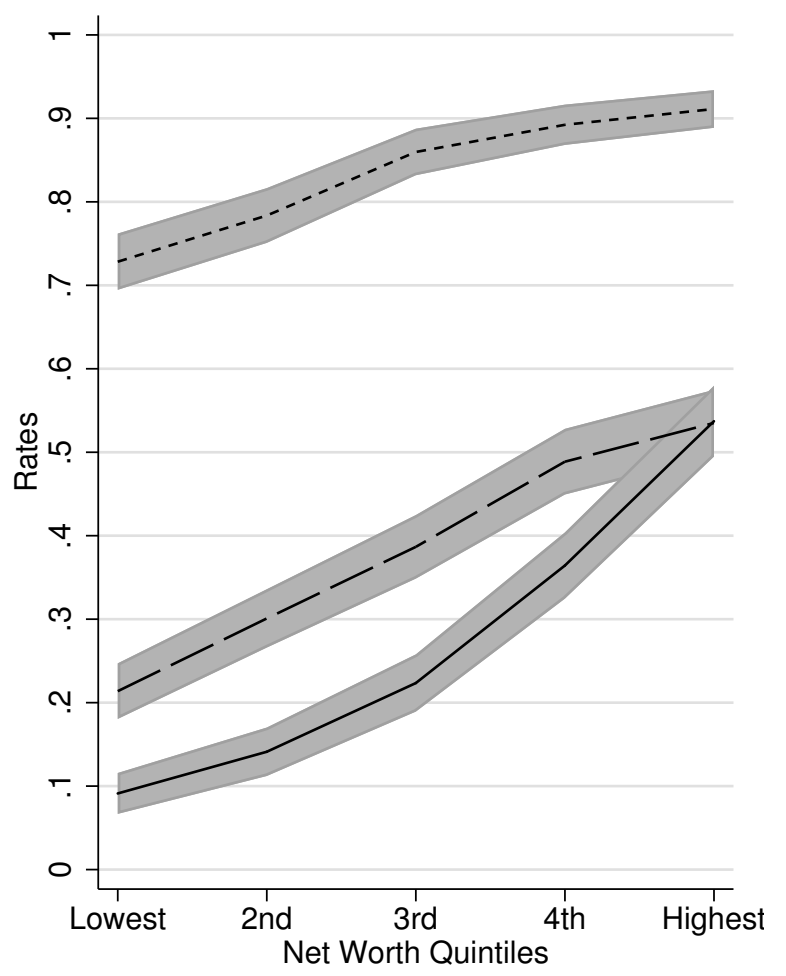

(b)

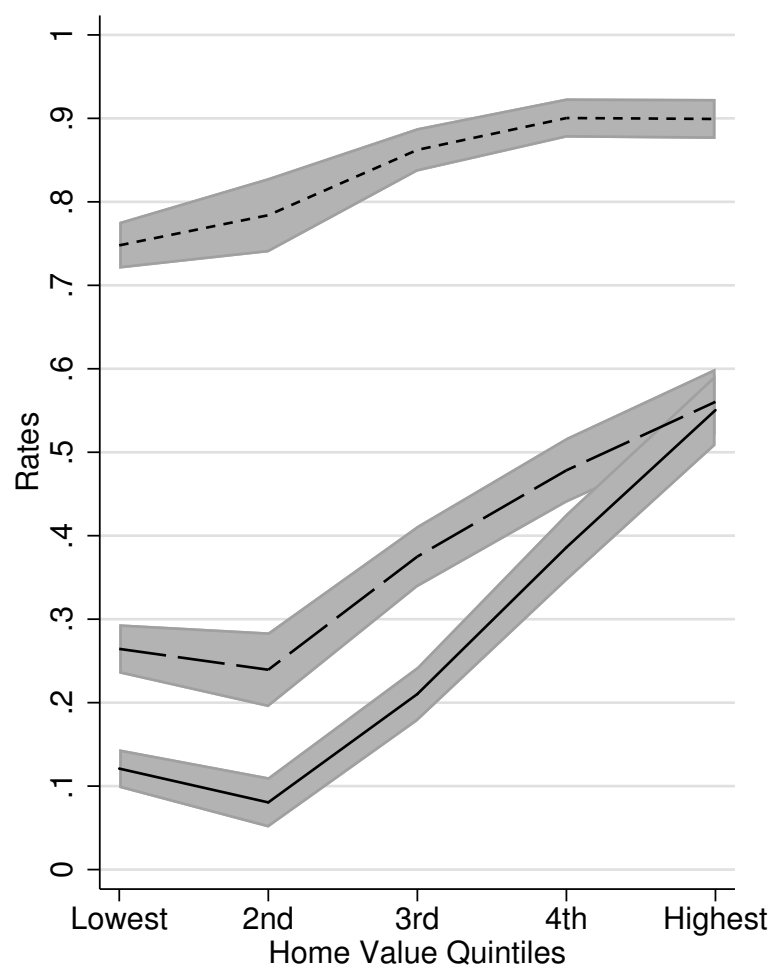

\section{-...-..- High School - - College Attendance — BA}

While the wealth gap in college graduation rates is enormous, it is of course not the case that every child from the wealthiest group assessed here graduates from college. As shown, overall, only about half of the children from the top wealth quintile receive a bachelor's 
degree. That should not come as a surprise to those familiar with estimates of college graduation rate among recent U.S. cohorts, which closely resemble those estimated here. ${ }^{6}$ With overall graduation rates at age 25 below 30 percent, even if no child from the bottom half of the wealth distribution were to graduate from college, one would still expect college graduation rates of less than 60 percent in the top half of the distribution. While it is thus a misperception that a great majority of children from wealthy households graduate college, it is certainly the case that the modal college graduate comes from a household with significant net worth. In this analytic sample, half of all college graduates come from a household with more than $\$ 190,000$ in net worth and a full fifth of them come from a household with at least half a million dollar net worth.

In addition to the assessment of gaps by families' net worth, Figure 1b also displays educational rates by home value quintiles. ${ }^{7}$ The degree and pattern of inequality in educational attainment by families' home values closely approximate those by families' net worth (Figure 1a). Though other wealth components, such as financial assets or home equity (home values minus mortgages), fare similarly well in approximating the reported net worth gaps (see Table A.2), home values provide in many ways the most attractive proxy measure. Substantively, home ownership constitutes the main asset component in most families' wealth portfolio. From a measurement perspective, home values are the easiest to collect among all asset components and, as such, appear to be a promising candidate to help remedy the data shortage that so far has hampered work on the relationship between family wealth and educational outcomes.

\footnotetext{
${ }^{6}$ Based on the Current Population Survey March Supplement, I estimate a college graduation rate for comparable individuals - specifically, individuals who are heads of households and age 25 in survey years 1995 through 2009 - of 28 percent compared to 27.2 percent in the analytic sample used here.

${ }^{7}$ Here, the lowest group contains those whose parents do not own a home (home value of zero), about 30 percent of the sample, while the second lowest group (about 10 percent of the sample) consists of children from owned homes valued at most about $\$ 64,000$ (see Table A.1). The remaining groups are standard quintiles (20 percent each).
} 


\section{Wealth as an independent source of educational advantage}

The large wealth gaps in educational outcomes described above can, of course, also arise from other correlated characteristics, not the least family income. Accordingly, the observed wealth gaps in education discussed above - and again displayed in Table 1, column "Uncontrolled" (now also including the outcome of college completion among those who have gained access to support a more direct assessment of college persistence) - are lower once controls for observable characteristics of parents and children are added (see list of controls discussed above). Still, wealth gaps in education adjusted for these controls (Table 1, column "Controlled") remain statistically and substantively significant: All else equal, the gap in educational attainment between children from the bottom quintile and children from the top quintile of the net worth distribution still (statistically significantly) differs by 6.4 percentage points for high school graduation, 8.4 percentage points for college access, 10.5 percentage points for college graduation, and 10.7 percentage points for college persistence.

It should be emphasized that the aim of these controlled models is not to provide a causal estimate of wealth effects (for recent evidence in this direction see Haellsten and Pfeffer 2017). Doing so faces many challenges, including the possibility of remaining unobserved bias (e.g. when joint determinants of family wealth and educational outcomes are not controlled), of endogenous controls (e.g. when a control variable, such as marital status in this analysis, may not only be a determinant of wealth and education but also a consequence of wealth; see Schneider 2011) and, with that, of endogenous selection bias induced by conditioning on a collider (e.g. when marital status a consequence of wealth and also related to further unobserved determinants of educational attainment; see Elwert and Winship 2014: pp. 44-45). Instead, the main aim in presenting estimates from these models is to compare educational gaps in wealth to those in income, which most other researchers focus on, underlining that something new can be learned from also taking into account wealth. Table 1 therefore reports 
Table 1: Wealth and Income Gaps in Education

\begin{tabular}{|c|c|c|c|c|c|c|}
\hline \multirow{5}{*}{$\begin{array}{l}\text { Wealth Quintile } \\
\text { 2nd }\end{array}$} & \multicolumn{6}{|c|}{$\begin{array}{c}\text { Change in Probability } \\
\text { Compared to lowest quintile (standard error) }\end{array}$} \\
\hline & \multicolumn{3}{|c|}{ Uncontrolled } & \multicolumn{3}{|c|}{ Controlled } \\
\hline & \multicolumn{6}{|c|}{ High School Graduation } \\
\hline & & & & & & \\
\hline & 0.0553 & $(0.0259)$ & $*$ & -0.0053 & $(0.0228)$ & \\
\hline $3 r d$ & 0.1315 & $(0.0246)$ & $* * *$ & 0.0456 & $(0.0240)$ & + \\
\hline 4 th & 0.1640 & $(0.0239)$ & $* * *$ & 0.0574 & $(0.0264)$ & $*$ \\
\hline Highest & 0.1830 & $(0.0237)$ & $* * *$ & 0.0643 & $(0.0302)$ & $*$ \\
\hline \multicolumn{7}{|l|}{ Income Quintile } \\
\hline 2nd & 0.0960 & $(0.0266)$ & $* * *$ & 0.0358 & $(0.0234)$ & \\
\hline $3 r d$ & 0.1509 & $(0.0251)$ & $* * *$ & 0.0456 & $(0.0260)$ & + \\
\hline 4 th & 0.1934 & $(0.0236)$ & $* * *$ & 0.0783 & $(0.0277)$ & $* *$ \\
\hline \multirow[t]{2}{*}{ Highest } & 0.2063 & $(0.0239)$ & $* * *$ & 0.0715 & $(0.0317)$ & $*$ \\
\hline & \multicolumn{6}{|c|}{ College Access } \\
\hline \multicolumn{7}{|l|}{ Wealth Quintile } \\
\hline 2nd & 0.0871 & $(0.0261)$ & $* * *$ & 0.0321 & $(0.0307)$ & \\
\hline $3 \mathrm{rd}$ & 0.1729 & $(0.0279)$ & $* * *$ & 0.0626 & $(0.0324)$ & + \\
\hline 4 th & 0.2749 & $(0.0276)$ & $* * *$ & 0.1011 & $(0.0357)$ & $* *$ \\
\hline \multirow{2}{*}{\multicolumn{7}{|c|}{ Income Quintile }} \\
\hline & & & & & & \\
\hline 2nd & 0.1124 & $(0.0265)$ & $* * *$ & 0.0684 & $(0.0320)$ & $*$ \\
\hline $3 \mathrm{rd}$ & 0.2192 & $(0.0261)$ & $* * *$ & 0.1186 & $(0.0333)$ & $* * *$ \\
\hline 4 th & 0.2663 & $(0.0268)$ & $* * *$ & 0.1139 & $(0.0360)$ & $* *$ \\
\hline \multirow[t]{2}{*}{ Highest } & 0.4083 & $(0.0259)$ & $* * *$ & 0.1996 & $(0.0413)$ & $* * *$ \\
\hline & \multicolumn{6}{|c|}{ Bachelor's Graduation } \\
\hline \multicolumn{7}{|l|}{ Wealth Quintile } \\
\hline 2nd & 0.0499 & $(0.0213)$ & $*$ & 0.0042 & $(0.0293)$ & \\
\hline $3 \mathrm{rd}$ & 0.1323 & $(0.0233)$ & $* * *$ & 0.0153 & $(0.0298)$ & \\
\hline 4 th & 0.2730 & $(0.0262)$ & $* * *$ & 0.0606 & $(0.0315)$ & + \\
\hline Highest & 0.4460 & $(0.0287)$ & $* * *$ & 0.1048 & $(0.0347)$ & $* *$ \\
\hline \multicolumn{7}{|l|}{ Income Quintile } \\
\hline 2nd & 0.0642 & $(0.0173)$ & $* * *$ & 0.0378 & $(0.0295)$ & \\
\hline $3 \mathrm{rd}$ & 0.1621 & $(0.0224)$ & $* * *$ & 0.0826 & $(0.0325)$ & $*$ \\
\hline 4 th & 0.3194 & $(0.0260)$ & $* * *$ & 0.1295 & $(0.0345)$ & $* * *$ \\
\hline \multirow[t]{2}{*}{ Highest } & 0.4979 & $(0.0265)$ & $* * *$ & 0.1659 & $(0.0386)$ & $* * *$ \\
\hline & \multicolumn{6}{|c|}{ BA conditional on Attendance } \\
\hline Wealth Quintile & & & & & & \\
\hline 2nd & 0.0695 & $(0.0403)$ & + & -0.0101 & $(0.0444)$ & \\
\hline $3 \mathrm{rd}$ & 0.1430 & $(0.0395)$ & $* * *$ & -0.0148 & $(0.0474)$ & \\
\hline 4 th & 0.2664 & $(0.0393)$ & $* * *$ & 0.0505 & $(0.0475)$ & \\
\hline Highest & 0.4263 & $(0.0380)$ & $* * *$ & 0.1071 & $(0.0517)$ & $*$ \\
\hline \multicolumn{7}{|l|}{ Income Quintile } \\
\hline 2nd & 0.0796 & $(0.0363)$ & $*$ & 0.0325 & $(0.0485)$ & \\
\hline $3 \mathrm{rd}$ & 0.1802 & $(0.0395)$ & $* * *$ & 0.0775 & $(0.0531)$ & \\
\hline 4 th & 0.3493 & $(0.0396)$ & $* * *$ & 0.1410 & $(0.0560)$ & $*$ \\
\hline Highest & 0.4640 & $(0.0377)$ & $* * *$ & 0.1583 & $(0.0579)$ & $* *$ \\
\hline
\end{tabular}

Note: $+\mathrm{p}<.10,{ }^{*} \mathrm{p}<.05,{ }^{* *} \mathrm{p}<.01,{ }^{* * *} \mathrm{p}<.001 ;$ standard errors are robust and clustered by PSID family lineage

Controlled $=$ Average marginal effects with controls for individuals' family background (family wealth, family income, parental occupational status, parental education, household size, number of children in the household, whether household head is married, mother's age), gender, and whether they have established their own household by age 20/25 (see also Table A.1). 
wealth gaps in education next to gaps by family income. ${ }^{8}$ For high school attainment, the observed gaps (column "Uncontrolled") are of similar size with a 18.4 and 20.6 percentage point difference between the top and the bottom quintiles of wealth and income, respectively. This similarity in the size of raw wealth and raw income gaps extends to estimates based on controlled regressions (column "Controlled"). Everything else equal, a change in family wealth from the bottom to the top quintile is associated with an increase in the probability of high school graduation by 6.4 percentage points and the same change in terms of family income, everything else equal, is associated with an additional increase by 7.2 percentage points. That is, family wealth and family income have independent and roughly equivalent predictive power for the attainment of a high school degree. In terms of college attainment, income gaps are larger than wealth gaps (both uncontrolled and controlled). In predicting the likelihood of a student gaining some college experience, family income appears to be more than twice as important as family wealth. Despite this dominating role of income in predicting college access, the overall difference in the relative importance of income and wealth is less pronounced for the attainment of a bachelor's degree. While a move from the bottom to the top family income quintile entails, everything else equal, an increase in bachelor's graduation rates by 16.6 percentage points, the same move in terms of family wealth still entails an additional 10.5 percentage point advantage (similar for college persistence) - large enough to conclude that the overall extent of educational inequality is captured incompletely when we neglect family wealth as an independent factor in educational attainment and, in particular, college graduation.

\footnotetext{
${ }^{8}$ This comparative assessment could be influenced by differences in the measurement error present in the income and wealth measures. Although separate assessments of the quality of PSID's income and wealth measures do exist (with generally positive conclusions, see Gouskova and Schoeni 2007; Pfeffer et al. 2016), it is difficult to draw firm conclusions about the relative degree of measurement error in these two variables. However, most researchers would probably be ready to assume more measurement error in wealth compared to income submitting that it may be more difficult to capture (e.g., when held in complex financial products) and more difficult for the respondent to recall and estimate (e.g. paycheck information is recent, home valuation may not be). If this assumption is correct, the estimated size of the wealth coefficients relative to that of the income coefficients would be underestimated, making for a conservative assessment of the relative importance of wealth.
} 


\section{Trends in wealth gaps in educational attainment}

The central question addressed here is whether the wealth gaps in education described so far (in Figure 1) have changed across an observation window of two decades. For this assessment, I compare the educational outcomes of children born in the 1970s (1970-1979) to children born in the 1980s (1980-1989). Figure 2 (see also Table A.3) displays rates of high school graduation, college access, college completion, and college persistence (completion among those who report some college experience) by family net worth quintiles for each of the two cohorts. The upper panel reports cohort-specific graduation rates, the lower panel displays the same information in a slightly different format, namely as the cohort difference in graduation rates with the earlier born cohort serving as the reference (consequently, positive slopes indicate growing wealth gaps) and 95 percent confidence intervals to allow the assessment of statistical significance of cohort differences (see Long and Freese 2014: p. 297ff for why statistical significance tests should be based on estimates of discrete change).

Starting with high school attainment, we observe that average graduation rates have increased among students from the bottom three wealth quintiles. For instance, children in the more recent cohort who grew up in the middle fifth of the wealth distribution have a graduation rate of 89.2 percent, which is 7.0 percentage points (and statistically significantly) above that of students from the middle fifth of the wealth distribution born a decade earlier. The high school attainment of students from the top two wealth quintiles, in contrast, has not changed in this time frame, a potential sign of saturation of this educational level among wealthier households. Overall, then, with the bottom 60 percent increasing their high school graduation rate and the top 40 percent largely stable, wealth inequality in high school attainment has decreased.

We also observe some signs of equalization in terms of college access: College access rates have tended to improve between these two cohorts across the distribution but most notably (and statistically significantly) for children from the middle wealth quintile, experiencing an 

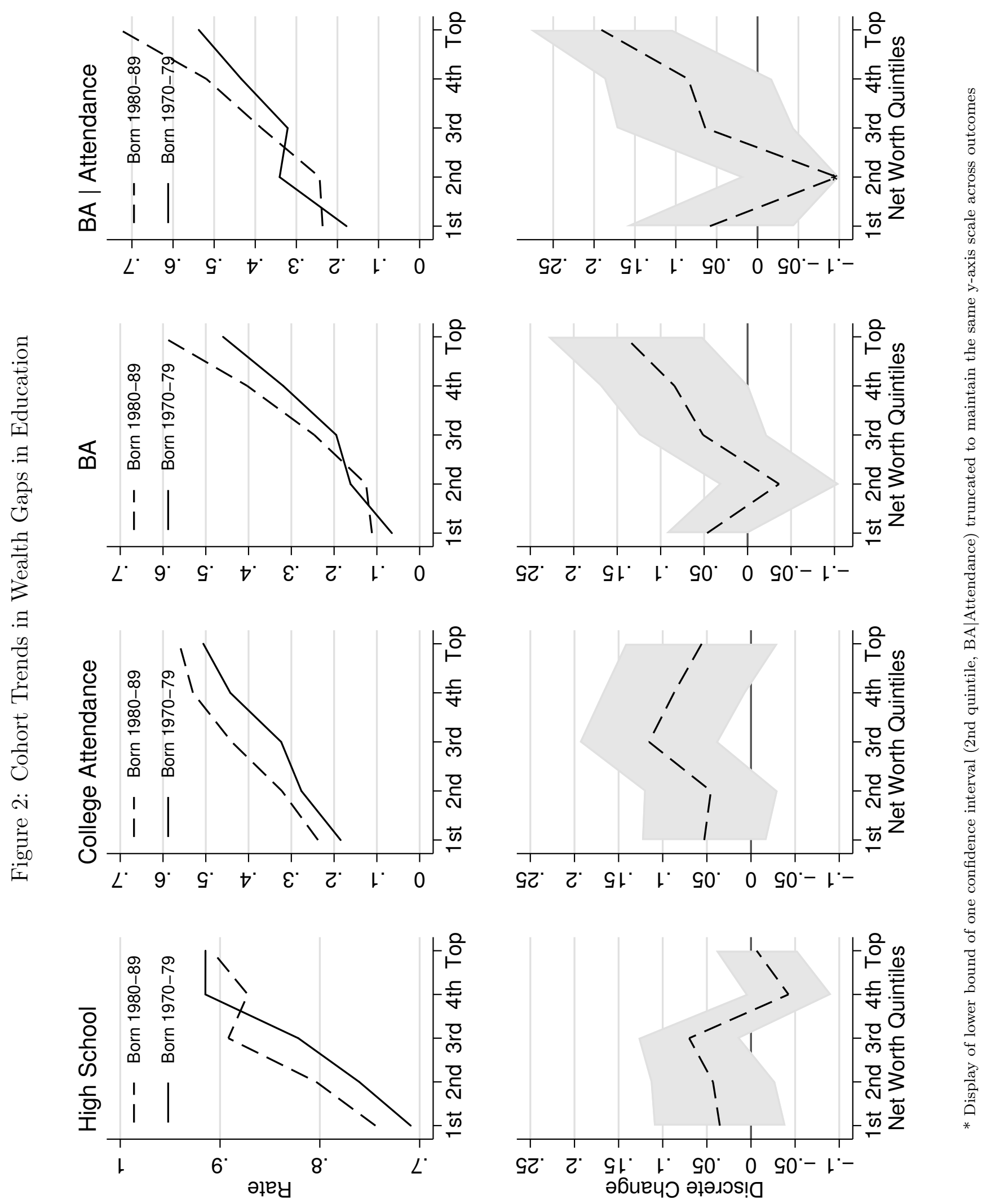
increase of 11.5 percentage points (from 32.4 to 43.9 percent). In contrast, college access rates among children from the top wealth quintile have expanded at a less rapid pace, with a statistically insignificant increase of 5.6 percentage points. As explained above, this may reflect the fact that college education has expanded faster than eligibility for it.

Trends in wealth gaps in college attainment are different and stark. Children from the bottom 60 percent of the wealth distribution were not able to make much progress over the decade studied here ${ }^{9}$ with statistically insignificant increases of 5 percentage points or less while children from the next 20 percent of the wealth distribution increased their college completion rates by 8.4 percentage points. The most marked increase, however, was experienced by children from the top 20 percent of the distribution. With a statistically significant increase in the college graduation rate of 14.1 percentage points in the span of just a decade, the wealthiest children have pulled away from others in terms of college attainment. That is, despite some decreases in wealth gaps in high school attainment and college access, the clearest and largest change in the distribution of educational opportunity lies in the rising gap between those from the top 20 percent of the wealth distribution and everyone else. As a result, while college graduation rates between those from the top and the bottom quintile of the wealth distribution differed by 39.5 percentage points among children who were born in the 1970s, it differed by a full 48.9 percentage points for children born a decade later; a growth of the wealth gap in college attainment by 9.4 percentage points in just a decade.

An increasing wealth gap in college graduation alongside some equalization of college access implies an exposed role of changing wealth differences in college persistence. The last column of Figure 2 serves to illustrate this point: The take-off in college graduation rates among students from the top wealth quintile is driven by a tremendous improvement in their college persistence rates, increasing from 53.7 to 72.9 percent, a full 19.1 percentage points, within a decade. The advantage in college persistence among the wealthiest fifth of students compared to even just those from the middle of the wealth distribution has grown by 12.7

\footnotetext{
${ }^{9}$ Stability analyses reported in Online Appendix S.4 further reinforce that conclusion.
} 
percentage points.

Finally, some readers may also be interested in cohort changes in the independent role of wealth, i.e. the potential growth of controlled wealth associations. The same cautions listed earlier against a causal interpretation of controlled wealth associations - based on the potential partial endogeneity of some controls and the potential presence of endogenous selection bias - also apply to the assessment of trends in controlled associations: To the degree that some controls are (also) endogenous, trends in their relationship with both wealth and educational outcomes can bias conclusions about trends in the effects of wealth. For instance, if marital status were to be increasingly determined by wealth or increasingly important for children's educational success, controlling for marital status may also control away some of the increasing effects of wealth. With these concerns in mind, I refer the interested reader to Figure 3 (see also Table A.4), which provides the same type of trend assessment as that presented in Figure 2 but based on regression models with the full set of controls (interacted by cohort to also allow for trends in the associations between each control and the outcomes). While the cohort trends in controlled wealth-education associations are, as expected, smaller than those in the uncontrolled wealth-education associations, the general conclusion from these results is that the cohort trends follow very similar patterns. ${ }^{10}$ The most pervasive trend continues to be the surge in the college attainment of college-going children from the top wealth quintile, reinforcing the conclusion drawn above about the exposed role played by the increased college persistence of the wealthiest students.

\footnotetext{
${ }^{10}$ Stability analyses based on linear probability models (see Online Appendix, Figure S.4) reveal only one notable difference, namely an even more pronounced increase in the growth of college attainment among children from the top wealth quintile; the main conclusion about growing wealth gaps in higher educational attainment based on average marginal effects from logistic regression models, as presented here, thus appears to be conservative.
} 


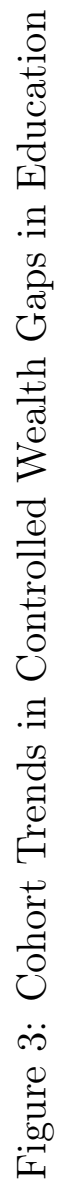
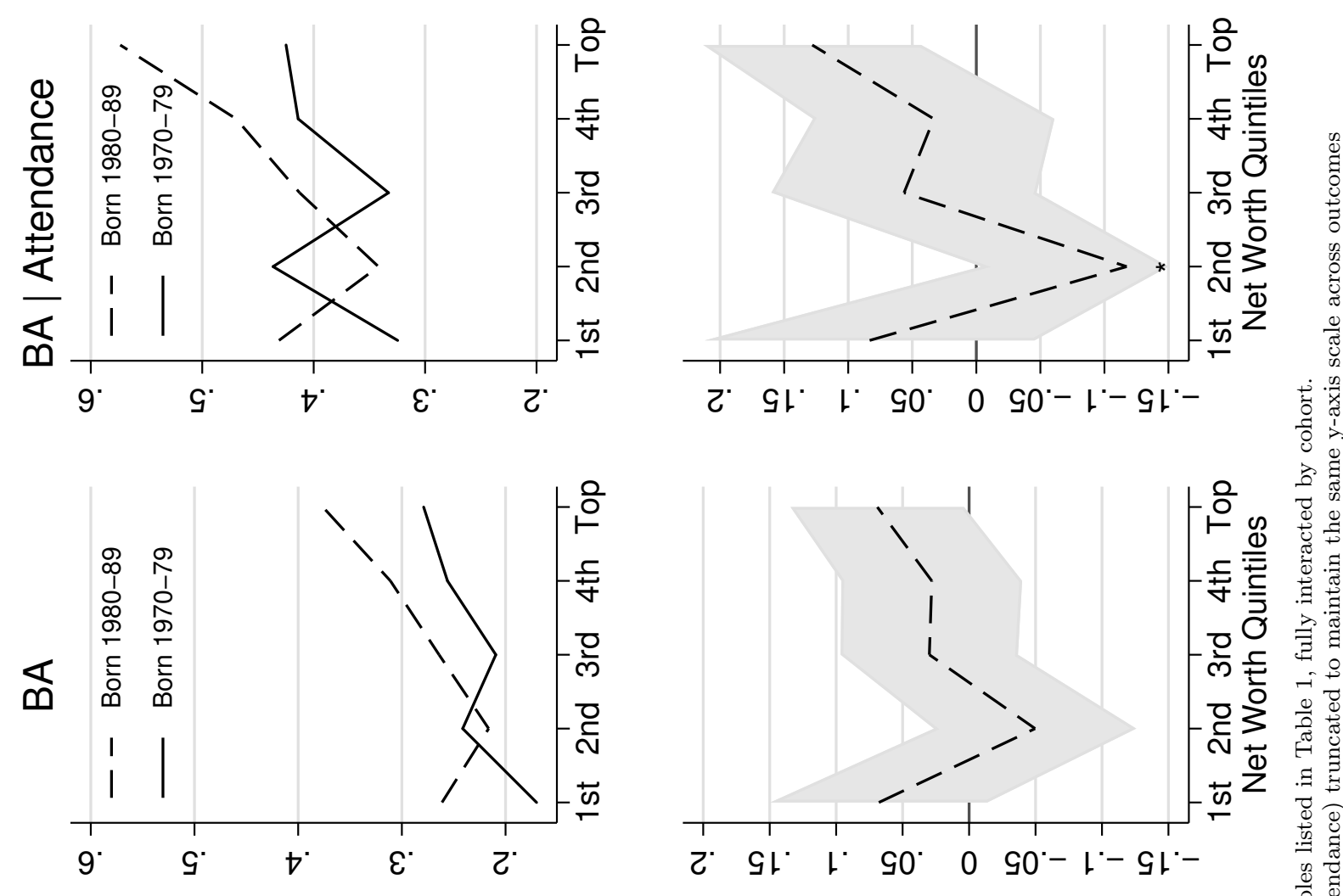

을

离

离

当

i

엥

$\exists$
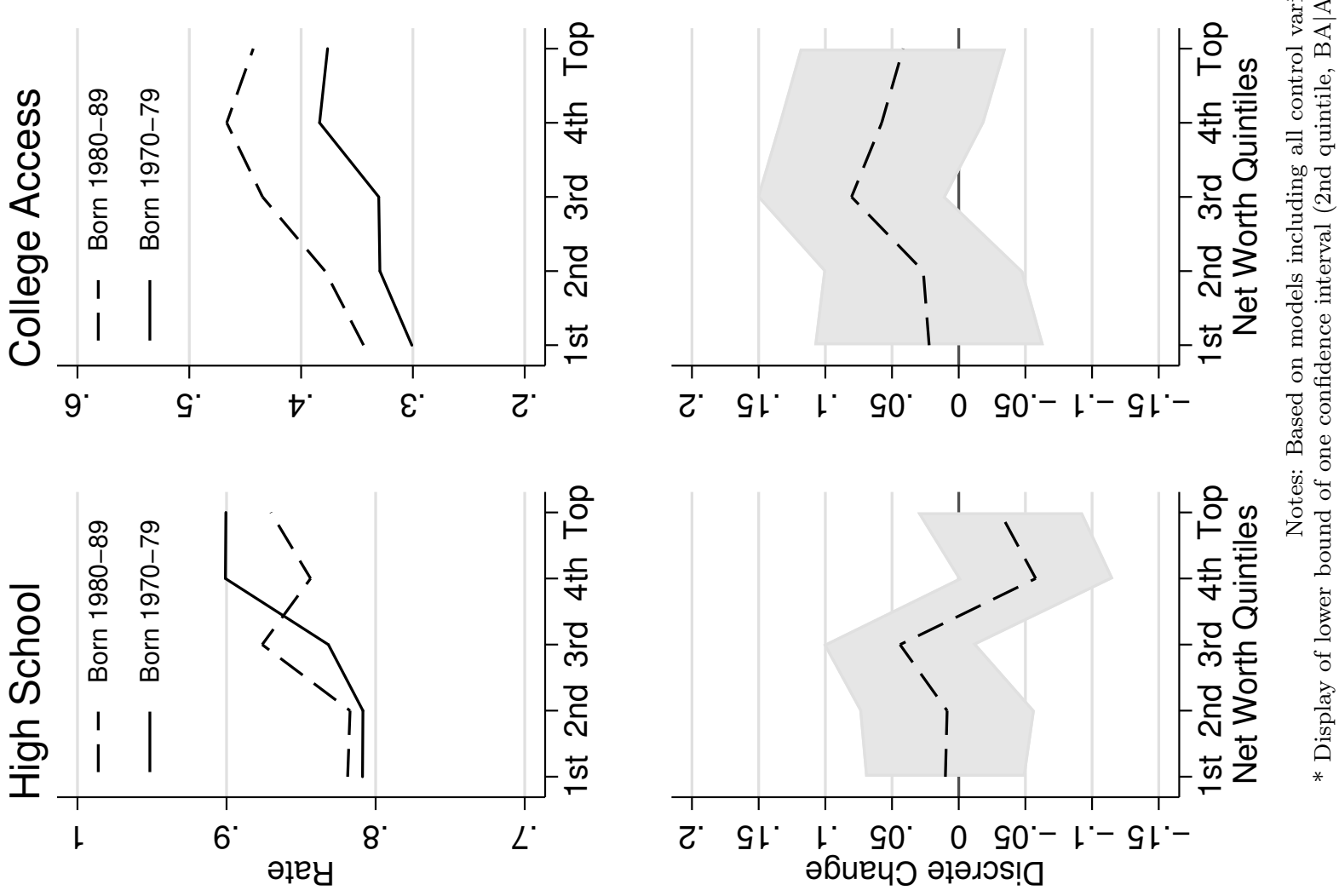


\section{Growing wealth gaps in college graduation in the context of rising wealth inequality}

In the remainder, I will focus on the growing wealth gap in college completion - as the most concerning finding yielded by the analyses so far - and assess to what degree it is related to the growth in wealth inequality. As argued above, while wealth may have become a more influential factor in determining college success, the fact alone that those at the top of the distribution have increasingly more wealth at their disposal than everyone else may also account for some of the growth in wealth gaps in education. I begin by describing the growth of wealth inequality among the children of the two cohorts studied here and also report on levels of wealth inequality among today's children (aged 10-14 in the latest available survey wave of 2015). I then describe the decomposition approach used to estimate the degree to which the observed rise in wealth inequality contributes to the documented increase in the wealth gap in college attainment.

Table 2 reports the median wealth among three groups of children: Those growing up in the bottom 80 percent of the family wealth distribution, the next ten percent, and the top ten percent. The differences in family wealth between these three groups are already high for the first cohort studied here: The median family net worth of children in the bottom four quintiles is $\$ 57,055$ (in 2015-\$), more than six times higher among those in the next ten percent $(\$ 361,406)$, and nearly 14 times higher among those in the top ten percent $(\$ 788,728)$. A decade later, the family wealth of children in the top quintile has increased further - much more strongly among the top ten percent than the next ten percent - but decreased substantially for the remaining 80 percent of children. As a result, in the second cohort, median wealth among children in the top ten percent is now 22 times higher than among those in the bottom 80 percent (and still 9 times higher among the next ten percent compared to those below). Another substantial shift occurred at the very bottom of the wealth distribution: While less than one in ten children of the earlier cohort come from 
Table 2: Trends in Wealth Inequality Among Children

\begin{tabular}{|c|c|c|c|}
\hline & \multicolumn{3}{|c|}{ Cohort } \\
\hline & $\begin{array}{r}\text { Earlier } \\
10-14 \text { in } 80 \mathrm{~s}\end{array}$ & $\begin{array}{r}\text { Later } \\
10-14 \text { in } 90 \mathrm{~s}\end{array}$ & $\begin{array}{r}\text { Current } \\
10-14 \text { in } 2015\end{array}$ \\
\hline \multicolumn{4}{|l|}{ Median net worth } \\
\hline Top $10 \%$ & 788,728 & 893,577 & $1,198,000$ \\
\hline Next $10 \%$ & 361,406 & 374,908 & 396,000 \\
\hline Bottom $80 \%$ & 57,055 & 39,977 & 21,000 \\
\hline \multicolumn{4}{|l|}{ Ratios } \\
\hline Top $10 \%$ / next $10 \%$ & 2.2 & 2.4 & 3.0 \\
\hline Top $10 \%$ / bottom $80 \%$ & 13.8 & 22.4 & 57.0 \\
\hline Next $10 \%$ / bottom $80 \%$ & 6.3 & 9.4 & 18.9 \\
\hline Share with zero/negative net worth & 0.097 & 0.137 & 0.231 \\
\hline Gini coefficient & 0.719 & 0.797 & 0.879 \\
\hline Gini coefficient (positive wealth) & 0.678 & 0.740 & 0.767 \\
\hline
\end{tabular}

families without any net worth (i.e., zero or negative net worth), that share rose to 13.7 percent of children in the later cohort. The rise in wealth inequality between these two cohorts is also reflected in the gini coefficient, which increased from 0.72 to 0.80 . The rise of asset non-ownership and indebtedness (zero and negative net worth) is an important driver of this increase as indicated by the fact that the gini coefficient among those with positive wealth rose slower than the gini coefficient across the entire distribution. ${ }^{11}$

The decomposition analysis reported below seeks to relate this increase in wealth inequality to the documented growth in the wealth gap in college attainment (see Duncan et al. 2017 for a similar type of analysis of family income gaps). Perhaps the most concerning outcome of such analysis would be to find that all of the increase in the wealth gap in college

\footnotetext{
${ }^{11}$ It should also be noted that distributions that include negative values, as is the case for wealth, can produce a gini coefficient above one.
} 
attainment can be traced to the growth of wealth inequality - since, as also shown in Table 2, wealth inequality is yet greater among today's children. Among children observed in the latest available PSID wave of 2015, wealth is even more heavily concentrated at the top: Children in the top ten percent of the distribution now typically grow up with about $\$ 1.2$ million in net worth, about 57 times the wealth of the bottom 80 percent of children whose typical family wealth is just $\$ 21,000$. Perhaps even more concerning, the share of children from households with zero or negative net worth has jumped by 10 percentage points to nearly a quarter of all children. The gini coefficient has also risen to 0.88 , again more rapidly when including the full distribution, indicating the importance of the growth of no asset holding and indebtedness. ${ }^{12}$ At the backdrop of such extreme level of wealth inequality among today's children, the growth in wealth inequality between earlier cohorts perhaps appears relatively low. Still, knowing whether this growth can be traced to the college outcomes of these children may inform our expectations about the fate of today's children.

The decomposition analysis relies on a piecewise spline regression model to predict the probability of college attainment (conditional and unconditional on college access), i.e.

$$
\begin{aligned}
\ln \left(\frac{p_{i}}{1-p_{i}}\right) & =\beta_{0}+\beta_{1} X_{i} & & X_{i} \leq a \\
& =\beta_{0}+\beta_{1} X_{i}+\beta_{2}\left(X_{i}-a\right) & & a<X_{i} \leq b \\
& =\beta_{0}+\beta_{1} X_{i}+\beta_{2}\left(X_{i}-a\right)+\beta_{3}\left(X_{i}-b\right) & & b<X_{i},
\end{aligned}
$$

where $X_{i}$ is an absolute measure of net worth and the spline knots ( $a$ and $b$ ) are set at specific absolute net worth values (to be described further below). The use of an absolute measure of wealth for this predictive model - instead of a relative measure, such as quintiles - is crucial to allow for the assessment of shifts in the wealth distribution. Here, the net worth variable $\left(X_{i}\right)$ is transformed using the inverse hyperbolic sine function (IHS; see Burbidge et al. 1988), which approximates the logarithmic function but allows the inclusion of cases with zero or negative net worth. The spline knots are set at net worth values

\footnotetext{
${ }^{12}$ Additional analyses reported in Online Appendix S.5 reveal that the gini coefficient of non-housing net worth (net worth excluding home equity) followed a similarly sharp increase, now reaching an astounding level of 0.98 (but see also footnote 11).
} 
representing the 80 th and 90 th percentiles of the unweighted wealth distribution among the earlier cohort and the full sample at age 25 (non-transformed net worth of $\$ 200,863$ and $\$ 378,160$, respectively). ${ }^{13}$ In a first step, I ascertain that this parsimonious specification of the relationship between family wealth and college attainment provides an acceptable approximation to the observed outcome of interest, namely the higher college graduation rates of children from the top wealth quintile. The top panel of Table 3 reports the probabilities of college attainment for children from the bottom four quintiles and children from the top quintile in the earlier birth cohort. The predicted probabilities are derived from the equation reported above and approximate the observed probabilities quite well: The predicted college graduation rate among all children from the bottom four quintiles is 17.6 percent compared to the observed 18.8 percent (33.5 percent vs. 34.2 percent among those who have gained college access). Similarly, 45.2 percent of children from the top quintile are predicted to attain a college degree compared to the observed college graduation rate of 46.0 percent (53.0 percent vs. 53.7 percent among those who have gained college access). The predicted and observed graduation gaps between these two groups are thus very similar -27.5 and 27.2 percentage points, respectively (and equivalent at 19.5 percentage points among those accessing college) - validating the choice of parametric form of the model applied here (see also Online Appendix S.6).

Next, the same predictive model is applied to the later cohort of children while constraining the parameter estimates to equal those estimated for the first cohort. That is, I now predict graduation rates for the later cohort based on their individual (IHS transformed) net worth but using the coefficients estimated based on the earlier cohort. In effect, this model assumes that the relationship between wealth and college outcomes observed in the earlier cohort remains constant but allows for changes in the wealth distribution between

\footnotetext{
${ }^{13}$ The specific model used here has been calibrated to provide the best empirical fit (discussed further below; see also Online Appendix S.6)
} 
Table 3: Decomposition Analysis

\begin{tabular}{|c|c|c|c|c|}
\hline & \multicolumn{2}{|c|}{ Probability of BA } & \multicolumn{2}{|c|}{ Prob. of BA $\mid$ Attendance } \\
\hline & Observed & Predicted & Observed & Predicted \\
\hline \multicolumn{5}{|l|}{ (1) Cohort born in $1970 \mathrm{~s}$} \\
\hline (1.1) Lowest four wealth quintiles & $18.8 \%$ & $17.6 \%$ & $34.2 \%$ & $33.5 \%$ \\
\hline (1.2) Highest wealth quintile & $46.0 \%$ & $45.2 \%$ & $53.7 \%$ & $53.0 \%$ \\
\hline (1.3) Gap [1.2-1.1] & $27.2 \%$ & $27.5 \%$ & $19.5 \%$ & $19.5 \%$ \\
\hline \multicolumn{5}{|l|}{ (2) Cohort born in 1980s } \\
\hline (2.1) Lowest four wealth quintiles & $22.1 \%$ & $17.0 \%$ & $36.8 \%$ & $32.4 \%$ \\
\hline (2.2) Highest wealth quintile & $60.1 \%$ & $46.0 \%$ & $72.7 \%$ & $53.5 \%$ \\
\hline (2.3) Gap [2.2-2.1] & $38.0 \%$ & $29.0 \%$ & $35.9 \%$ & $21.1 \%$ \\
\hline (3) Cohort difference in gap [2.3-1.3] & $10.8 \%$ & $1.4 \%$ & $16.4 \%$ & $1.6 \%$ \\
\hline (4) Growth in gap accounted for & & $13.1 \%$ & & $9.5 \%$ \\
\hline
\end{tabular}

the two cohorts. ${ }^{14}$ The extent to which the predicted college graduation rates produced by this model replicate the observed graduation rates for the later cohort indicates the extent to which changes in the wealth distribution, namely growing wealth inequality, accounts for changes in wealth gaps in college attainment: If changing wealth gaps in college attainment were entirely driven by the change in wealth inequality between these two cohorts, the predicted and the observed wealth gaps for the second cohort would be the same. However, as shown in the second panel of Table 3, the predicted and observed wealth gaps in college graduation diverge from each other, mostly because applying the wealth effects estimated in the earlier cohort to the wealth distribution of the later cohort underestimates the college attainment of the top quintile (46.0 percent versus 60.1 percent among all, 53.5 percent versus 72.7 percent among those accessing college), that is, it misses most of the surge in

\footnotetext{
${ }^{14}$ Furthermore, in the context of the specific model applied here, I also need to assume that the parametrization of the model remains equally valid, i.e. the absolute thresholds chosen for the spline knots that were drawn based on the earlier cohort remain equally useful for the later cohort.
} 
college attainment and persistence at the top established in the prior section. As a result, the predicted wealth gap in college attainment is much smaller than observed (29.0 vs. 38.0 percentage points among all, 21.1 vs. 35.9 percentage points among those accessing college). While the wealth gap in college attainment between the top quintile and everyone else rose by 10.8 percentage points between these two cohorts (by 16.4 percentage points for those accessing college), the rise predicted by assuming a stable association between wealth and college attainment is only 1.4 percentage points (1.6 percentage points for those accessing college).

Overall, then, the conclusion is that the rise in wealth inequality alone explains only a limited share of the growth in the gap in college attainment between the wealthiest 20 percent of students and the rest - less than a sixth (13.1 percent) among all and less than a tenth (9.5 percent) among those accessing college. Although a decomposition of the wealth gap in education controlled for other observed characteristics (reported in Appendix Table A.5) reveals a potentially larger contribution of growing wealth inequality to the growth of controlled associations between parental wealth and college attainment (explaining about a third of the growth in the wealth gap in college attainment among all and about a quarter among those accessing college), the main conclusion is that the increase in wealth inequality between these two cohorts is far from fully reflected in the increase in wealth gaps in their later college attainment. This may qualify as good news at the backdrop of the extreme level of wealth inequality among today's children. Given this result, it also does not seem reasonable to interpolate from the gaps in college attainment observed here to gaps in the future college attainment of today's children based on the level of wealth inequality they currently experience. Such interpolation may also be inadmissible for another reason: As described in detail in Appendix B, the parental wealth of many members of the second cohort included here was likely subject to significant fluctuation in the run-up to and during the Great Recession. The possibility that such period effects underlie the trends established here prohibits inferring a broader, secular trend towards growing wealth gaps that extends 
to current cohorts.

Still, the possibility that the growing inequality in college attainment stems primarily from changes in the importance of wealth for college success (rather than from changes in the distribution of wealth), should embolden policy efforts geared at reducing the inequitable effects of wealth on higher educational attainment. Short of such changes, today's children can at the very least be expected to continue to encounter a remarkably high level of wealth inequality in their college opportunities.

\section{CONCLUSION}

This paper describes gaps in educational attainment by family wealth and their change over two recent cohorts, born in the 1970s and 1980s, respectively. In line with prior research (e.g. Conley 2001), substantial gaps in educational attainment by family net worth can be observed across all educational levels - namely, high school attainment, college access, and college graduation - and the role of family wealth in predicting these educational outcomes is independent of that of other socio-economic characteristics of families, including family income. Most pressingly, however, this paper provides the first evidence that wealth inequality in college graduation has been rising further over recent cohorts, with the college graduation rates of children from higher wealth backgrounds surging while children from lower wealth levels have been left behind. The extent of this surge in wealth inequality in college attainment is profound: Among children born between 1970 and 1979, the college graduation rate among those who grew up in the top 20 percent of the wealth distribution was 39.5 percentage points higher than among those who grew up in the bottom 20 percent. However, for children born only a decade later, that wealth gap in college attainment has grown to 48.9 percentage points. This rapid increase in wealth inequality in college attainment is especially concerning because the stakes of college completion have also been rising, both at the individual and at the societal level: Not only do individuals' opportunities to attain 
comfortable earnings increasingly depend on the completion of a bachelor's degree, but it is also widely acknowledged that the country's international competitiveness and economic growth depend heavily on a highly educated work-force (Goldin and Katz 2008).

The documented increase in wealth inequality in college attainment is also particularly notable as wealth gaps at lower levels of educational attainment show signs of decrease: In terms of high school attainment, the least wealthy students have made further inroads while this level of educational attainment had already been largely saturated among students from higher wealth backgrounds. Also, I document advances in college access among children from the middle of the wealth distribution relative to others. As a consequence, the documented growth in the wealth gap in college attainment must be driven by growing inequality in college persistence. I accordingly also document a surge in college persistence among the wealthiest children: Just above half (53.7 percent) of the wealthiest children born in the 1970s who had gained access to college also attained a bachelor's degree compared to 72.9 percent of those born in the 1980s, an increase in college persistence rates at the top of the wealth distribution by a full 19.1 percentage points in just a decade. In sum, then, the findings reported here suggest that efforts to equalize educational opportunities as they relate to family wealth need to go beyond the expansion of college access for children from lower wealth backgrounds and put particular emphasis on also leading these students towards college graduation (see Bailey and Dynarski 2011 for an equivalent argument related to parental income).

Furthermore, I have described that the documented growth in wealth inequality in college attainment occurs in the context of rising inequality in the wealth origins of the children studied here. This widening distance in their wealth origins, however, is far from fully reflected in the rising wealth gap in their college graduation rates. That is, the growth in educational inequality between these two cohorts is not primarily driven by widening wealth inequality itself and may instead arise from the increasing importance of family wealth. The contrary finding - rising wealth inequality fully accounting for rising wealth gaps in education - would have made predictions about the fate of today's children particularly bleak since the 
level of wealth inequality they experience substantially exceeds that observed in the cohorts studied here and can only be described as extreme (e.g. with a gini coefficient of 0.88 ).

Independent of this take-off in wealth inequality, the results reported here raise concerns about the increasing association between family wealth and college attainment. Efforts to reduce this association should, as already mentioned, also focus on the ways in which family wealth facilitates college persistence. While this contribution does not seek to establish causality and much less the causal pathways through which family wealth affects educational outcomes, the theoretical arguments provided may guide future research in explaining the increasing role of wealth for college persistence: Rising direct financial transfers from wealthy parents to their offspring (Rauscher 2016) may increasingly be geared at supporting college students in staying or getting back on track rather than transferring to other institutions or stopping out as they face academic challenges (Goldrick-Rab and Pfeffer 2009). Furthermore, wealth inequality in college persistence and attainment is likely also established in children's earlier educational experiences, for instance, as children from wealthier households attend high schools that leave them academically better prepared for college and thereby also facilitate access to colleges with higher retention rates, such as highly competitive and prestigious four-year schools (Bastedo and Jaquette 2011).

This last observation also points to one of the limitations of this contribution and opportunities for future research: This study does not investigate "horizontal" differences in education, for instance, wealth gaps by institution type and selectivity (but see Jez 2014). Yet, as children from the wealthiest families have reached saturation of educational participation at the secondary level and more children from wealth backgrounds below the top are accessing higher education (as documented here), the wealthiest households may increasingly exploit these types of horizontal differences in the educational system to effectively maintain inequality (Lucas 2001; Gerber and Cheung 2008). In this sense, the growth of wealth inequality in college attainment shown here may still provide a conservative estimate. Furthermore, the growth of college enrollment among those from the middle of the 
wealth distribution may be less hopeful a sign of progress to the extent that it may be driven by enrollment in subpar and predatory for-profit colleges that does not translate into a bachelor's degree (McMillan Cottom 2017). Future research may draw on new data - including restricted-use PSID data available for a a subset of the individuals included here - to identify the type of college attended, distinguishing 4-year and 2-year, public and private, profit and not-for-profit, as well as selective and non-selective colleges. Doing so holds promise for the explanation of the documented large and growing wealth gaps in college persistence: The assessment of different institutional types of colleges may reveal that the wealthiest students have increased their advantage in college attainment chiefly by attending the types of post-secondary institutions that have the highest retention rates.

Another way in which the presented analyses may underestimate the degree of wealth inequality in education is due to its exclusive focus on the immediate family: Advantages arising from family wealth may extend beyond the parent-child dyad as the wealth of grandparents or even wealth in extended family networks may additionally facilitate educational success (Roksa and Potter 2011; Prix and Pfeffer 2017; Haellsten and Pfeffer 2017). Revealingly, many college campuses around the country have begun to complement their family visit day with a portion dedicated to grandparents (e.g. Feiler 2014).

Finally, the finding that home values serve as a powerful proxy measure of wealth gaps in education may be particularly important to help expand the research base and facilitate future research. Home value indicators are more easily collected than full-fledged asset survey modules and often readily accessible through administrative or linked external data. For instance, drawing on home values to approximate wealth gaps in education may allow historical assessments of wealth inequality in education (e.g. based on the housing values reported on the publicly available 1940 U.S. Census), longer-term assessments of additional cohorts (e.g. based on the housing information consistently observed in the PSID since 1968), or detailed analyses of wealth gaps in college pathways based on administrative data held by colleges and states that also include the addresses of students' pre-college residence (for 
which external real estate data yield home value estimates).

The documented role of home values in approximating wealth gaps in education, however, also goes beyond a measurement issue. It poses the question to what extent wealth effects on education are in fact asset effects, effects of housing quality (e.g., Lopoo and London 2016), and effects of the neighborhoods in which highly-valued houses are located (Sampson et al. 2002; Durlauf 2004). The broad but largely separate literatures that exist on each of these potential channels that link housing wealth to educational success urgently await integration. 


\section{REFERENCES}

Arum, Richard, Adam Gamoran, and Yossi Shavit. 2007. "More Inclusion Than Diversion: Expansion, Differentiation, and Market Structure in Higher Education." In Stratification in Higher Education. A Comparative Study, edited by Yossi Shavit, Richard Arum, and Adam Gamoran, pp. 1-38. Stanford, CA: Stanford University Press.

Axinn, William, Greg J. Duncan, and Arland Thornton. 1997. "The Effects of Parents' Income, Wealth and Attitudes on Children's Completed Schooling and Self-Esteem." In Consequences of Growing Up Poor, edited by Greg J. Duncan and Jeanne Brooks-Gunn, pp. 518-540. New York: Russell Sage Foundation.

Bailey, Martha J. and Susan M. Dynarski. 2011. "Inequality in Postsecondary Education." In Whither Opportunity? Rising Inequality, Schools, and Children's Life Chances, edited by Greg J. Duncan and Richard J. Murnane, pp. 117-131. New York: Russell Sage Foundation.

Bastedo, M. N. and O. Jaquette. 2011. "Running in Place: Low-Income Students and the Dynamics of Higher Education Stratification." Educational Evaluation and Policy Analysis 33:318-339.

Belley, Philippe and Lance Lochner. 2007. "The Changing Role of Family Income and Ability in Determining Educational Achievement." Journal of Human Capital 1:37-89.

Bloome, D. and B. Western. 2011. "Cohort Change and Racial Differences in Educational and Income Mobility." Social Forces 90:375-395.

Brady, David, Anke Radenacker, Marco Giesselmann, and Ulrich Kohler. ???? "Proxying Permanent Income in Germany and U.S." Journal of Economic Inequality (forthcoming).

Buchmann, Claudia, Dennis Condron, and Vincent Roscigno. 2010. "Shadow Education, American Style. Test Preparation, the SAT and College Enrollment." Social Forces 89:435462.

Buchmann, Claudia and Thomas A DiPrete. 2006. "The Growing Female Advantage in College Completion. The Role of Family Background and Academic Achievement." American Sociological Review 71:515-541.

Burbidge, John B., Lonnie Magee, and A. Leslie Robb. 1988. "Alternative Transformations to Handle Extreme Values of the Dependent Variable." Journal of the American Statistical Association 83:123-127.

Cameron, Stephen V and Christopher Taber. 2004. "Estimation of Educational Borrowing Constraints Using Returns to Schooling." Journal of Political Economy 112:132-182.

Chetty, Raj, Nathaniel Hendren, Patrick Kline, Emmanuel Saez, and Nicholas Turner. 2014. "Is the United States still a land of opportunity? Recent trends in intergenerational mobility." NBER Working Paper Series 19844. 
\{College Board\}. 2015. Trends in College Pricing. New York: The College Board.

Conley, Dalton. 1999. Being Black, Living in the Red. Race, Wealth, and Social Policy in America. Berkeley: University of California Press.

Conley, Dalton. 2001. "Capital for College. Parental Assets and Postsecondary Schooling." Sociology of Education 74:59-72.

Duncan, Greg J., Ariel Kalil, and Kathleen M. Ziol-Guest. 2017. "Increasing Inequality in Parent Incomes and Children's Schooling." Demography 54:1603-1626.

Durlauf, Steven N. 2004. "Neighborhood Effects." In Handbook of Regional and Urban Economics, edited by J. Vernon Henderson and Jacques-Francois Thisse, volume 4, pp. 2173-2242. Elsevier.

Dynarski, Susan. 2002. "Loans, liquidity and schooling decisions." Kennedy School of Government Working Paper.

Elwert, Felix and Christopher Winship. 2014. "Endogenous Selection Bias: The Problem of Conditioning on a Collider Variable." Annual Review of Sociology 40:31-53.

Feiler, Bruce. 2014. "College Family Weekend Isn't Just for Parents Anymore." The New York Times .

Frank, Robert H. and Philip J. Cook. 1996. The Winner-Take-All Society: Why the Few at the Top Get So Much More Than the Rest of Us. New York: Penguin Books, reprint edition edition.

Gale, William G. and John Karl Scholz. 1994. "Intergenerational Transfers and the Accumulation of Wealth." Journal of Economic Perspectives 8:145-160.

Gerber, Theodore P. and Sin Yi Cheung. 2008. "Horizontal Stratification in Postsecondary Education. Forms, Explanations, and Implications." Annual Review of Sociology 34:299318.

Goldin, Claudia and Lawrence F. Katz. 2008. The Race between Education and Technology. Cambridge: Harvard University Press.

Goldrick-Rab, Sara and Fabian T. Pfeffer. 2009. "Beyond Access. Explaining Socioeconomic Differences in College Transfer." Sociology of Education 82:101-125.

Gouskova, Elena and Robert Schoeni. 2007. "Comparing Estimates of Family Income in the PSID and the March Current Population Survey, 1968-2005." PSID Technical Paper \#0\%-01.

Hacker, Jacob S. 2007. The Great Risk Shift. The New Economic Insecurity and the Decline of the American Dream. Oxford: Oxford University Press.

Haellsten, Martin and Fabian T. Pfeffer. 2017. "Grand advantage: Family wealth and grandchildren's educational attainment in Sweden." American Sociological Review 82:328-360. 
Hanmer, Michael J. and Kerem Ozan Kalkan. 2013. "Behind the Curve. Clarifying the Best Approach to Calculating Predicted Probabilities and Marginal Effects from Limited Dependent Variable Models." American Journal of Political Science 57:263-277.

Harding, David J., Christopher Jencks, Leonard M. Lopoo, and Susan E. Mayer. 2004. "The Changing Effect of Family Background on the Incomes of American Adults." In Unequal Chances: Family Background and Economic Success, edited by Samuel Bowles, Herbert Gintis, and Anastasiya M. Osborne. Princeton: Princeton University Press.

Haurin, Donald R, Toby L Parcel, and R Jean Haurin. 2002. "Does Homeownership Affect Child Outcomes?" Real Estate Economics 30:635-666.

Hauser, Robert M. 1993. "Trends in College Entry among Whites, Blacks, and Hispanics: 1972-1988." In Studies of Supply and Demand in Higher Education, edited by Charles Clotfelter and Michael Rothschild, pp. 61-104. Chicago: University Of Chicago Press.

Haveman, Robert and Kathryn Wilson. 2007. "Access, Matriculation, and Graduation." In Economic Inequality and Higher Education. Access, Persistence, and Success, edited by Stacy Dickert-Conlin and Ross Rubenstein. New York: Russell Sage Foundation.

Hertz, Tom, Tamara Jayasundera, Patrizio Piraino, Sibel Selcuk, Nicole Smith, and Alina Verashchagina. 2007. "The Inheritance of Educational Inequality. International Comparisons and Fifty-Year Trends." The B.E. Journal of Economic Analysis and Policy 7:1-46.

Hout, Michael and Daniel P Dohan. 1996. "Two Paths to Educational Opportunity. Class and Educational Selection in Sweden and the United States." In Can Education Be Equalized? The Swedish Case in Comparative Perspective, edited by Robert Erikson and Jan O Jonsson, pp. 207-232. Boulder: Westview Press.

Hout, Michael and Alexander Janus. 2011. "Educational Mobility in the United States Since the 1930s." In Whither Opportunity? Rising Inequality, Schools, and Children's Life Chances, edited by Greg J. Duncan and Richard J. Murnane, pp. 165-185. New York: Russell Sage Foundation.

Hout, Michael, Adrian E Raftery, and Eleanor O Bell. 1993. "Making the Grade: Educational Stratification in the United States, 1925-1989." In Persistent Inequality. Educational Attainment in Thirteen Countries, edited by Yossi Shavit and Hans-Peter Blossfeld, Social Inequality Series, pp. 25-49. Boulder / San Francisco / Oxford: Westview Press.

Jez, Su Jin. 2014. "The Differential Impact of Wealth Versus Income in the College-Going Process." Research in Higher Education 55:710-734.

Johnson, Rucker C. 2012. "The Impact of Parental Wealth on College Enrollment \& Degree Attainment: Evidence from the Housing Boom \& Bust." Unpublished Manuscript .

Juster, F. Thomas, James P. Smith, and Frank Stafford. 1999. "The measurement and structure of household wealth." Labour Economics 6:253-275. 
Kaushal, Neeraj, Katherine Magnuson, and Jane Waldfogel. 2011. "How is family income related to investments in children's learning?" In Whither Opportunity?: Rising Inequality, Schools, and Children's Life Chances, edited by Greg J. Duncan and Richard Murnane, pp. 187-206. New York: Russell Sage Foundation.

Keister, Lisa A. 2000. Wealth in America. Trends in Wealth Inequality. Cambridge: Cambridge University Press.

Keister, Lisa A. and Stephanie Moller. 2000. "Wealth Inequality in the United States." Annual Review of Sociology 26:63-81.

Khan, Shamus Rahman. 2012. Privilege. The Making of an Adolescent Elite at St. Paul's School. Princeton: Princeton University Press.

Killewald, Alexandra, Fabian T. Pfeffer, and Jared N. Schachner. 2017. "Wealth Inequality and Accumulation." Annual Review of Sociology 43.

Kornrich, Sabino and Frank Furstenberg. 2012. "Investing in Children. Changes in Parental Spending on Children, 1972-2007." Demography 50:1-23.

Leslie, Larry L. and Paul T. Brinkman. 1987. "Student Price Response in Higher Education: The Student Demand Studies." The Journal of Higher Education 58:181-204.

Long, Bridget Terry. 2014. "The Financial Crisis and College Enrollment: How Have Students and Their Families Responded?" In How the Financial Crisis and Great Recession Affected Higher Education, edited by Jeffre R. Brown and Caroline M. Hoxby, pp. 209-233. Chicago, IL: University Of Chicago Press.

Long, Scott J. and Jeremy Freese. 2014. Regression Models for Categorical Dependent Variables Using Stata. College Station, TX: Stata Press.

Lopoo, Leonard M. and Andrew S. London. 2016. "Household Crowding During Childhood and Long-Term Education Outcomes." Demography 53:699-721.

Lovenheim, Michael F. 2011. "The Effect of Liquid Housing Wealth on College Enrollment." Journal of Labor Economics 29:741-771.

Lucas, Samuel R. 2001. "Effectively Maintained Inequality. Education Transitions, Track Mobility, and Social Background Effects." American Journal of Sociology 106:1642-1690.

Mare, Robert. 1981. "Change and Stability in Educational Stratification." American Sociological Review 46:72-87.

Mayer, Susan E. 1997. What Money Can't Buy. Family Income and Children's Life Chances. Cambridge: Harvard University Press.

McCabe, Brian J. 2016. No Place Like Home: Wealth, Community and the Politics of Homeownership. New York, NY: Oxford University Press, 1 edition edition. 
McGarry, Kathleen and Robert F. Schoeni. 1995. "Transfer Behavior in the Health and Retirement Study: Measurement and the Redistribution of Resources within the Family." The Journal of Human Resources 30:S184-S226.

McMillan Cottom, Tressie. 2017. Lower Ed: The Troubling Rise of For-Profit Colleges in the New Economy. New York: The New Press.

Morgan, Stephen L and Young-Mi Kim. 2006. "Inequality of Conditions and Intergenerational Mobility. Changing Patterns of Educational Attainment in the United States." In Mobility and Inequality. Frontiers of Research in Sociology and Economics, edited by Stephen L Morgan, David B Grusky, and Gary S Fields, pp. 165-194. Stanford: Stanford University Press.

\{National Center for Education Statistics\}. 2016a. Common Core of Data. Washington, D.C.

\{National Center for Education Statistics\}. 2016b. Digest of Education Statistics. Washington, D.C.

Oliver, Melvin L and Thomas M Shapiro. 1997. Black Wealth, White Wealth. A New Perspective on Racial Inequality. New York: Routledge.

Oliver, Melvin L and Thomas M Shapiro. 2006. Black Wealth, White Wealth. A New Perspective on Racial Inequality (Tenth-Anniversary Edition). New York: Routledge.

Orr, Amy J. 2003. "Black-White Differences in Achievement. The Importance of Wealth." Sociology of Education 76:281-304.

Owens, Ann. 2016. "Inequality in Children's Contexts. Income Segregation of Households with and without Children." American Sociological Review 81:549-574.

Owens, Ann, Sean F. Reardon, and Christopher Jencks. 2016. "Income Segregation between Schools and Districts, 1990 to 2010." Center for Education Policy Analysis Working Paper No. 16-04.

Panel Study of Income Dynamics. 2017. Public Use Dataset. Produced and distributed by the by the Survey Research Center, Institute for Social Research, University of Michigan, Ann Arbor, MI.

Pfeffer, Fabian T. 2008. "Persistent Inequality in Educational Attainment and its Institutional Context." European Sociological Review 24:543-565.

Pfeffer, Fabian T. 2011. "Status Attainment and Wealth in the United States and Germany." In Persistence, Privilege, and Parenting, edited by Timothy M Smeeding, Robert Erikson, and Markus Jaentti, pp. 109-137. New York: Russell Sage Foundation.

Pfeffer, Fabian T., Sheldon H. Danziger, and Robert F. Schoeni. 2013. "Wealth Disparities Before and After the Great Recession." Annals of the American Academy of Political and Social Science 650:98-123. 
Pfeffer, Fabian T and Martin Haellsten. 2012. "Mobility Regimes and Parental Wealth: The United States, Germany, and Sweden in Comparison." Population Studies Center Research Report 12-766.

Pfeffer, Fabian T. and Florian R. Hertel. 2015. "How Has Educational Expansion Shaped Social Mobility Trends in the United States?" Social Forces 94:143-180.

Pfeffer, Fabian T. and Robert F. Schoeni. 2016. "How Wealth Inequality Shapes Our Future." Russell Sage Foundation Journal of the Social Sciences 6:2-22.

Pfeffer, Fabian T., Robert F. Schoeni, Arthur B. Kennickell, and Patricia Andreski. 2016. "Measuring Wealth and Wealth Inequality: Comparing Two U.S. Surveys." Journal of Economic and Social Measurement 41:103-120.

Piketty, T. and G. Zucman. 2014. "Capital is Back: Wealth-Income Ratios in Rich Countries 1700-2010." The Quarterly Journal of Economics 129:1255-1310.

Prix, Irene and Fabian T. Pfeffer. 2017. "Does Donald Need Uncle Scrooge? Extendedfamily wealth and children's educational attainment in the United States." In Social Inequality across the Generations. The Role of Resource Compensation and Multiplication in Resource Accumulation (forthcoming), edited by Jani Erola and Elina Kilpi-Jakonen. Cheltenham: Edward Elgar Publishing.

Raftery, Adrian E and Michael Hout. 1993. "Maximally Maintained Inequality. Expansion, Reform, and Opportunity in Irish Education 1921-75." Sociology of Education 66:41-62.

Rauscher, Emily. 2016. "Passing It On. Parent-to-Adult Child Financial Transfers for School and Socioeconomic Attainment." Russell Sage Foundation Journal of the Social Sciences 2:172-196.

Reardon, Sean F. 2011. "The Widening Academic Achievement Gap between the Rich and the Poor." In Whither Opportunity? Rising Inequality, Schools, and Children's Life Chances, edited by Greg J Duncan and Richard J. Murnane, pp. 91-115. New York: Russell Sage Foundation.

Reardon, Sean F and Kendra Bischoff. 2011. "Income Inequality and Income Segregation." American Journal of Sociology 116:1092-1153.

Roksa, Josipa, Eric Grodsky, Richard Arum, and Adam Gamoran. 2007. "Changes in Higher Education and Social Stratification in the United States." In Stratification in Higher Education. A Comparative Study, edited by Yossi Shavit, Richard Arum, and Adam Gamoran, pp. 165-191. Stanford: Stanford University Press.

Roksa, Josipa and Daniel Potter. 2011. "Parenting and Academic Achievement: Intergenerational Transmission of Educational Advantage." Sociology of Education 84:299-321.

Saez, Emmanuel and Gabriel Zucman. 2014. "Wealth Inequality in the United States Since 1913. Evidence from Capitalized Income Tax Data." NBER Working Paper Series 20625. 
Sampson, Robert J., Jeffrey D. Morenoff, and Thomas Gannon-Rowley. 2002. "Assessing "Neighborhood Effects": Social Processes and New Directions in Research." Annual Review of Sociology 28:443-478.

Schneider, Daniel. 2011. "Wealth and the Marital Divide." American Journal of Sociology 117:627-667.

Schoeni, Robert F. and Karen E. Ross. 2005. "Material assistance from families during the transition to adulthood." In On the Frontier of Adulthood, edited by Richard A. Settersten and Frank F. Furstenberg, pp. 396-416.

Shapiro, Thomas M. 2004. The Hidden Cost of Being African American. How Wealth Perpetuates Inequality. Oxford: Oxford University Press.

Shavit, Yossi and Hans-Peter Blossfeld. 1993. Persistent Inequality. Changing Educational Attainment in Thirteen Countries. Boulder: Westview Press.

Taylor, Paul and Richard Fry. 2012. "The Rise of Residential Segregation by Income." Pew Social $\& 5$ Demographic Trends .

Treiman, Donald J. 1970. "Industrialization and Social Stratification." In Social Stratification. Research and Theory for the 1970s, edited by Edward O Laumann, pp. 207-234. Indianapolis: Bobbs-Merrill.

von Hippel, Paul T. 2007. "Regression with Missing Ys. An Improved Strategy for Analyzing Multiply Imputed Data." Sociological Methodology 31:83-117.

Watson, Tara. 2009. "Inequality and the Measurement of Residential Segregation by Income in American Neighborhoods." Review of Income and Wealth 55:820-844.

Wolff, Edward N. 1995. Top Heavy. A study of the increasing inequality of wealth in America. New York: Twentieth Century Fund Press.

Wolff, Edward N. 2016. "Household Wealth Trends in the United States, 1962 to 2013. What Happened over the Great Recession?" Russell Sage Foundation Journal of the Social Sciences 2:24-43.

Yeung, W Jean and Dalton Conley. 2008. "Black-White Achievement Gap and Family Wealth." Child Development 79:303-324.

Ziol-Guest, Kathleen M. and Kenneth T. H. Lee. 2016. "Parent Income-Based Gaps in Schooling." AERA Open 2:1-10. 


\section{A Appendix: Additional Tables}

\section{A.1 Descriptive Statistics}

\begin{tabular}{|c|c|c|c|c|c|c|}
\hline & \multicolumn{3}{|c|}{ Sample at age 20} & \multicolumn{3}{|c|}{ Sample at age 25} \\
\hline & All & Born 1970s & Born 1980s & All & Born 1970s & Born 1980s \\
\hline \multicolumn{7}{|l|}{ Outcomes } \\
\hline High School Graduation & $\begin{array}{c}0.835 \\
(0.371)\end{array}$ & $\begin{array}{l}0.826 \\
(0.379)\end{array}$ & $\begin{array}{c}0.843 \\
(0.364)\end{array}$ & & & \\
\hline College Access & $\begin{array}{l}0.385 \\
(0.487)\end{array}$ & $\begin{array}{l}0.349 \\
(0.477)\end{array}$ & $\begin{array}{l}0.417 \\
(0.493)\end{array}$ & & & \\
\hline College Graduation & & & & $\begin{array}{c}0.272 \\
(0.445)\end{array}$ & $\begin{array}{c}0.242 \\
(0.429)\end{array}$ & $\begin{array}{l}0.296 \\
(0.456)\end{array}$ \\
\hline \multicolumn{7}{|l|}{ Wealth } \\
\hline Net Worth (in 1,000$)$ & $\begin{array}{c}230.244 \\
(811.717)\end{array}$ & $\begin{array}{c}224.685 \\
(772.203)\end{array}$ & $\begin{array}{c}235.054 \\
(844.525)\end{array}$ & $\begin{array}{c}237.733 \\
(1010.358)\end{array}$ & $\begin{array}{c}219.323 \\
(718.188)\end{array}$ & $\begin{array}{c}252.546 \\
(1194.595)\end{array}$ \\
\hline Home Value (in 1,000) & $\begin{array}{c}139.352 \\
(182.387)\end{array}$ & $\begin{array}{c}134.739 \\
(183.552)\end{array}$ & $\begin{array}{c}143.343 \\
(181.312)\end{array}$ & $\begin{array}{c}140.311 \\
(178.012)\end{array}$ & $\begin{array}{c}136.857 \\
(170.352)\end{array}$ & $\begin{array}{l}143.09 \\
(183.933)\end{array}$ \\
\hline Home Equity (in 1,000 ) & $\begin{array}{c}75.973 \\
(136.089)\end{array}$ & $\begin{array}{c}84.267 \\
(143.552)\end{array}$ & $\begin{array}{c}68.797 \\
(128.882)\end{array}$ & $\begin{array}{c}75.807 \\
(128.888)\end{array}$ & $\begin{array}{c}83.599 \\
(121.996)\end{array}$ & $\begin{array}{c}69.538 \\
(133.873)\end{array}$ \\
\hline Financial Assets (in 1,000) & $\begin{array}{c}68.591 \\
(559.163)\end{array}$ & $\begin{array}{c}50.925 \\
(531.662)\end{array}$ & $\begin{array}{c}83.876 \\
(581.573)\end{array}$ & $\begin{array}{c}81.148 \\
(731.093)\end{array}$ & $\begin{array}{c}56.169 \\
(579.647)\end{array}$ & $\begin{array}{l}101.248 \\
(832.776)\end{array}$ \\
\hline \multicolumn{7}{|c|}{$\begin{array}{l}\text { Median wealth (by quintiles) } \\
\text { Net Worth (in } 1,000)\end{array}$} \\
\hline Lowest quintile & $\begin{array}{c}0 \\
{[-1277.9 ; 4.8]}\end{array}$ & $\begin{array}{c}0 \\
{[-932.3 ; 6.8]}\end{array}$ & $\begin{array}{c}0 \\
{[-1277.9 ; 4.3]}\end{array}$ & $\begin{array}{c}0 \\
{[-1277.9 ; 5.0]}\end{array}$ & $\begin{array}{c}0 \\
{[-932.3 ; 8.4]}\end{array}$ & $\begin{array}{c}0 \\
{[-1277.9 ; 3.3]}\end{array}$ \\
\hline 2nd quintile & $\begin{array}{c}21.3 \\
{[4.9 ; 45.5]}\end{array}$ & $\begin{array}{c}25.6 \\
{[6.9 ; 47.9]}\end{array}$ & $\begin{array}{c}18.4 \\
{[4.3 ; 41.6]}\end{array}$ & $\begin{array}{c}22.9 \\
{[5.0 ; 46.1]}\end{array}$ & $\begin{array}{c}29.7 \\
{[8.5 ; 53.5]}\end{array}$ & $\begin{array}{c}16.8 \\
{[3.4 ; 40.0]}\end{array}$ \\
\hline 3rd quintile & $\begin{array}{c}73.3 \\
{[45.6 ; 107.0]}\end{array}$ & $\begin{array}{c}76.5 \\
{[48.0 ; 103.8]}\end{array}$ & $\begin{array}{c}71.4 \\
{[41.7 ; 111.9]}\end{array}$ & $\begin{array}{c}75.8 \\
{[46.1 ; 110.7]}\end{array}$ & $\begin{array}{c}79.9 \\
{[53.6 ; 110.7]}\end{array}$ & $\begin{array}{c}69.7 \\
{[40.2 ; 108.1]}\end{array}$ \\
\hline 4th quintile & $\begin{array}{c}164.7 \\
{[107.1 ; 269.6]}\end{array}$ & $\begin{array}{c}156.6 \\
{[105.0 ; 246.0]}\end{array}$ & $\begin{array}{c}176.4 \\
{[112.3 ; 284.6]}\end{array}$ & $\begin{array}{c}170.7 \\
{[110.9 ; 273.4]}\end{array}$ & $\begin{array}{c}164.8 \\
{[110.9 ; 269.9]}\end{array}$ & $\begin{array}{c}173 \\
{[109.6 ; 279.8]}\end{array}$ \\
\hline Highest quintile & $\begin{array}{c}503.4 \\
{[269.9 ; 26127.2]}\end{array}$ & $\begin{array}{c}498.7 \\
{[246.7 ; 20811.4]}\end{array}$ & $\begin{array}{c}505.3 \\
{[287.2 ; 26127.2]}\end{array}$ & $\begin{array}{c}508.6 \\
{[273.4 ; 26127.2]}\end{array}$ & $\begin{array}{c}520.3 \\
{[270.4 ; 20811.4]}\end{array}$ & $\begin{array}{c}501.3 \\
{[282.4 ; 26127.2]}\end{array}$ \\
\hline Overall & 75.1 & 78.3 & 70.4 & 76.8 & 84.6 & 67.2 \\
\hline Home Value (in 1,000 ) & & & & & & \\
\hline Lowest quintile & $\begin{array}{c}0 \\
{[0.0 ; 0.0]}\end{array}$ & $\begin{array}{c}0 \\
{[0.0 ; 0.0]}\end{array}$ & $\begin{array}{c}0 \\
{[0.0 ; 0.0]}\end{array}$ & $\begin{array}{c}0 \\
{[0.0 ; 0.0]}\end{array}$ & $\begin{array}{c}0 \\
{[0.0 ; 0.0]}\end{array}$ & $\begin{array}{c}0 \\
{[0.0 ; 0.0]}\end{array}$ \\
\hline
\end{tabular}


Table A.1(continued)

\begin{tabular}{|c|c|c|c|c|c|c|}
\hline & \multicolumn{3}{|c|}{ Sample at age 20} & \multicolumn{3}{|c|}{ Sample at age 25} \\
\hline & All & Born 1970s & Born 1980s & All & Born 1970s & Born 1980s \\
\hline 2nd quintile & 36.3 & 34.4 & 36.8 & 36.8 & 45.6 & 35.2 \\
\hline 3rd quintile & $\begin{array}{c}{[0.0 ; 64.0]} \\
95.9\end{array}$ & $\begin{array}{c}{[1.4 ; 63.9]} \\
95.6\end{array}$ & $\begin{array}{c}{[0.0 ; 64.0]} \\
103.7\end{array}$ & $\begin{array}{c}{[0.0 ; 64.0]} \\
99.6\end{array}$ & $\begin{array}{c}{[1.4 ; 72.7]} \\
98.5\end{array}$ & $\begin{array}{c}{[0.0 ; 59.8]} \\
99.6\end{array}$ \\
\hline & {$[64.0 ; 128.1]$} & {$[64.0 ; 124.3]$} & {$[64.0 ; 142.3]$} & {$[64.1 ; 133.9]$} & {$[73.0 ; 125.5]$} & {$[60.8 ; 142.3]$} \\
\hline 4th quintile & $\begin{array}{c}170.7 \\
{[129.5: 219.1]}\end{array}$ & $\begin{array}{c}159.8 \\
{[125.5 ; 194.0]}\end{array}$ & $\begin{array}{c}185 \\
{[143.7 ; 239.9]}\end{array}$ & $\begin{array}{c}172.1 \\
{[134.3 ; 223.9]}\end{array}$ & $\begin{array}{c}162.5 \\
{[127.8 ; 198.6]}\end{array}$ & $\begin{array}{c}185 \\
{[143.7 ; 239.9]}\end{array}$ \\
\hline Highest quintile & $\begin{array}{c}320.1 \\
{[219.9 ; 1912.2]}\end{array}$ & $\begin{array}{c}306 \\
{[195.0 ; 1912.2]}\end{array}$ & $\begin{array}{c}343.8 \\
{[241.9 ; 1912.2]}\end{array}$ & $\begin{array}{c}334.6 \\
{[225.6 ; 1565.1]}\end{array}$ & $\begin{array}{c}306 \\
{[199.7 ; 1242.9]}\end{array}$ & $\begin{array}{c}351.8 \\
{[241.9 ; 1565.1]}\end{array}$ \\
\hline Overall & 95.9 & 95.6 & 99.6 & 99.6 & 98.5 & 99.6 \\
\hline \multicolumn{7}{|l|}{ Other SES } \\
\hline Income (in 1,000 ) & $\begin{array}{c}92.126 \\
(92.126)\end{array}$ & $\begin{array}{c}83.486 \\
(64.639)\end{array}$ & $\begin{array}{c}99.600 \\
(109.989)\end{array}$ & $\begin{array}{c}92.669 \\
(89.901)\end{array}$ & $\begin{array}{c}85.506 \\
(66.319)\end{array}$ & $\begin{array}{c}98.433 \\
(104.761)\end{array}$ \\
\hline Occupational Status & $\begin{array}{c}485.380 \\
(233.664)\end{array}$ & $\begin{array}{c}469.368 \\
(234.642)\end{array}$ & $\begin{array}{c}499.232 \\
(231.968)\end{array}$ & $\begin{array}{c}488.751 \\
(233.896)\end{array}$ & $\begin{array}{c}480.698 \\
(232.850)\end{array}$ & $\begin{array}{c}495.231 \\
(234.583)\end{array}$ \\
\hline Parental Education, $<\mathrm{HS}$ & $\begin{array}{c}0.106 \\
(0.308)\end{array}$ & $\begin{array}{l}0.14 \\
(0.347)\end{array}$ & $\begin{array}{c}0.077 \\
(0.267)\end{array}$ & $\begin{array}{c}0.101 \\
(0.301)\end{array}$ & $\begin{array}{c}0.124 \\
(0.330)\end{array}$ & $\begin{array}{c}0.082 \\
(0.275)\end{array}$ \\
\hline Parental Education, HS & $\begin{array}{l}0.312 \\
(0.463)\end{array}$ & $\begin{array}{l}0.359 \\
(0.480)\end{array}$ & $\begin{array}{c}0.272 \\
(0.445)\end{array}$ & $\begin{array}{l}0.305 \\
(0.460)\end{array}$ & $\begin{array}{c}0.347 \\
(0.476)\end{array}$ & $\begin{array}{l}0.271 \\
(0.444)\end{array}$ \\
\hline Parental Education, Some College & $\begin{array}{l}0.295 \\
(0.456)\end{array}$ & $\begin{array}{l}0.258 \\
(0.438)\end{array}$ & $\begin{array}{l}0.327 \\
(0.469)\end{array}$ & $\begin{array}{l}0.297 \\
(0.457)\end{array}$ & $\begin{array}{c}0.262 \\
(0.440)\end{array}$ & $\begin{array}{l}0.325 \\
(0.469)\end{array}$ \\
\hline Parental Education, BA & $\begin{array}{l}0.286 \\
(0.452)\end{array}$ & $\begin{array}{c}0.243 \\
(0.429)\end{array}$ & $\begin{array}{c}0.324 \\
(0.468)\end{array}$ & $\begin{array}{l}0.297 \\
(0.457)\end{array}$ & $\begin{array}{c}0.267 \\
(0.443)\end{array}$ & $\begin{array}{c}0.322 \\
(0.467)\end{array}$ \\
\hline \multicolumn{7}{|l|}{ Demographics } \\
\hline Female & $\begin{array}{c}0.491 \\
(0.500)\end{array}$ & $\begin{array}{c}0.482 \\
(0.500)\end{array}$ & $\begin{array}{c}0.499 \\
(0.500)\end{array}$ & $\begin{array}{c}0.486 \\
(0.500)\end{array}$ & $\begin{array}{c}0.475 \\
(0.500)\end{array}$ & $\begin{array}{c}0.495 \\
(0.500)\end{array}$ \\
\hline Family Size & $\begin{array}{l}4.409 \\
(1.245)\end{array}$ & $\begin{array}{c}4.461 \\
(1.250)\end{array}$ & $\begin{array}{c}4.364 \\
(1.239)\end{array}$ & $\begin{array}{c}4.394 \\
(1.239)\end{array}$ & $\begin{array}{c}4.431 \\
(1.235)\end{array}$ & $\begin{array}{l}4.365 \\
(1.241)\end{array}$ \\
\hline Number of Children in Family & $\begin{array}{l}2.466 \\
(1.065)\end{array}$ & $\begin{array}{l}2.458 \\
(1.070)\end{array}$ & $\begin{array}{c}2.472 \\
(1.060)\end{array}$ & $\begin{array}{l}2.455 \\
(1.063)\end{array}$ & $\begin{array}{l}2.426 \\
(1.060)\end{array}$ & $\begin{array}{c}2.478 \\
(1.065)\end{array}$ \\
\hline Household Head Married & $\begin{array}{c}0.766 \\
(0.423)\end{array}$ & $\begin{array}{l}0.798 \\
(0.401)\end{array}$ & $\begin{array}{l}0.738 \\
(0.440)\end{array}$ & $\begin{array}{l}0.765 \\
(0.424)\end{array}$ & $\begin{array}{l}0.806 \\
(0.396)\end{array}$ & $\begin{array}{c}0.732 \\
(0.443)\end{array}$ \\
\hline Mother's Age & $\begin{array}{l}37.571 \\
(5.588)\end{array}$ & $\begin{array}{l}36.762 \\
(5.497)\end{array}$ & $\begin{array}{l}38.272 \\
(5.572)\end{array}$ & $\begin{array}{l}37.798 \\
(5.648)\end{array}$ & $\begin{array}{l}37.089 \\
(5.581)\end{array}$ & $\begin{array}{l}38.368 \\
(5.639)\end{array}$ \\
\hline Own Household (Age 20) & $\begin{array}{c}0.213 \\
(0.410)\end{array}$ & $\begin{array}{l}0.205 \\
(0.404)\end{array}$ & $\begin{array}{c}0.220 \\
(0.415)\end{array}$ & & & \\
\hline Own Household (Age 25) & & & & $\begin{array}{l}0.756 \\
(0.430)\end{array}$ & $\begin{array}{c}0.771 \\
(0.420)\end{array}$ & $\begin{array}{c}0.744 \\
(0.437)\end{array}$ \\
\hline $\mathrm{N}$ & 5,025 & 2,334 & 2,691 & 4,344 & 1,799 & 2,545 \\
\hline
\end{tabular}




\section{A.2 Wealth Gaps in Education}

\begin{tabular}{|c|c|c|c|c|c|c|c|c|c|c|c|c|}
\hline & \multicolumn{3}{|c|}{ High School Graduation } & \multicolumn{3}{|c|}{ College Attendance } & \multicolumn{3}{|c|}{ Bachelor's Graduation } & \multicolumn{3}{|c|}{ BA $\mid$ Attendance } \\
\hline & \multirow[t]{2}{*}{ Rate } & \multicolumn{2}{|c|}{$(95 \%$ C.I. $)$} & \multirow[t]{2}{*}{ Rate } & \multicolumn{2}{|c|}{ (95\% C.I. $)$} & \multirow[t]{2}{*}{ Rate } & \multicolumn{2}{|c|}{ (95\% C.I.) } & \multirow[t]{2}{*}{ Rate } & \multicolumn{2}{|c|}{ (95\% C.I. $)$} \\
\hline \multicolumn{9}{|c|}{ Net Worth Quintile } & & & & \\
\hline Lowest & 0.7283 & $(0.6947$ & $0.7620)$ & 0.2138 & $(0.1805$ & $0.2471)$ & 0.0912 & $(0.0667$ & $0.1157)$ & 0.2144 & $(0.1603$ & $0.2685)$ \\
\hline 2nd & 0.7836 & $(0.7508$ & $0.8165)$ & 0.3009 & 0.2660 & $0.3359)$ & 0.1411 & 0.1122 & $0.1701)$ & 0.2839 & $(0.2316$ & $0.3363)$ \\
\hline $3 \mathrm{rd}$ & 0.8598 & $(0.8319$ & $0.8876)$ & 0.3867 & $(0.3486$ & $0.4247)$ & 0.2235 & $(0.1892$ & $0.2578)$ & 0.3574 & $(0.3077$ & $0.4072)$ \\
\hline 4 th & 0.8923 & $(0.8682$ & $0.9165)$ & 0.4887 & $(0.4494$ & $0.5280)$ & 0.3643 & $(0.3246$ & $0.4039)$ & 0.4808 & $(0.4334$ & $0.5282)$ \\
\hline Highest & 0.9113 & $(0.8887$ & $0.9338)$ & 0.5352 & $(0.4956$ & $0.5748)$ & 0.5372 & $(0.4948$ & $0.5796)$ & 0.6408 & $(0.5960$ & $0.6856)$ \\
\hline \multicolumn{13}{|c|}{ Home Value Quintile } \\
\hline Lowest & 0.7479 & $(0.7199$ & $0.7759)$ & 0.2644 & $(0.2349$ & $0.2939)$ & 0.1210 & $(0.0978$ & $0.1442)$ & 0.2532 & $(0.2083$ & $0.2980)$ \\
\hline 2nd & 0.7840 & $(0.7395$ & $0.8286)$ & 0.2394 & $(0.1946$ & $0.2842)$ & 0.0805 & $(0.0503$ & $0.1107)$ & 0.1987 & $(0.1293$ & $0.2680)$ \\
\hline $3 r d$ & 0.8623 & $(0.8362$ & $0.8884)$ & 0.3750 & $(0.3381$ & $0.4118)$ & 0.2103 & $(0.1776$ & $0.2430)$ & 0.3439 & $(0.2955$ & $0.3923)$ \\
\hline 4 th & 0.9004 & $(0.8769$ & $0.9239)$ & 0.4783 & $(0.4394$ & $0.5172)$ & 0.3861 & $(0.3456$ & $0.4266)$ & 0.5021 & $(0.4550$ & $0.5493)$ \\
\hline Highest & 0.8993 & $(0.8754$ & $0.9233)$ & 0.5605 & $(0.5206$ & $0.6003)$ & 0.5505 & $(0.5080$ & $0.5929)$ & 0.6436 & $(0.5990$ & $0.6883)$ \\
\hline \multicolumn{13}{|c|}{ Home Equity Quintile } \\
\hline Lowest & 0.7561 & $(0.7297$ & $0.7825)$ & 0.2728 & $(0.2444$ & $0.3012)$ & 0.1275 & $(0.1050$ & $0.1499)$ & 0.2620 & $(0.2194$ & $0.3046)$ \\
\hline 2nd & 0.8383 & $(0.7943$ & $0.8824)$ & 0.3135 & $(0.2558$ & $0.3712)$ & 0.1654 & $(0.1157$ & $0.2151)$ & 0.3379 & $(0.2484$ & $0.4274)$ \\
\hline $3 r d$ & 0.8464 & $(0.8183$ & $0.8744)$ & 0.3765 & $(0.3394$ & $0.4135)$ & 0.2122 & $(0.1793$ & $0.2451)$ & 0.3460 & $(0.2976$ & $0.3944)$ \\
\hline 4 th & 0.8915 & $(0.8673$ & $0.9157)$ & 0.4514 & $(0.4132$ & $0.4895)$ & 0.3592 & $(0.3200$ & $0.3985)$ & 0.4915 & $(0.4438$ & $0.5391)$ \\
\hline Highest & 0.8937 & $(0.8688$ & $0.9186)$ & 0.5375 & $(0.4971$ & $0.5780)$ & 0.5203 & $(0.4773$ & $0.5633)$ & 0.6271 & $(0.5810$ & $0.6732)$ \\
\hline \multicolumn{13}{|c|}{ Financial Assets Quintile } \\
\hline Lowest & 0.7094 & $(0.6745$ & $0.7444)$ & 0.1901 & $(0.1599$ & $0.2203)$ & 0.0726 & $(0.0517$ & $0.0934)$ & 0.2037 & $(0.1490$ & $0.2584)$ \\
\hline 2nd & 0.7875 & $(0.7553$ & $0.8196)$ & 0.3129 & $(0.2773$ & $0.3484)$ & 0.1447 & $(0.1153$ & $0.1742)$ & 0.2722 & $(0.2215$ & $0.3229)$ \\
\hline $3 \mathrm{rd}$ & 0.8618 & $(0.8349$ & 0.8887 ) & 0.3957 & $(0.3567$ & $0.4347)$ & 0.2597 & $(0.2225$ & $0.2968)$ & 0.3655 & $(0.3168$ & $0.4142)$ \\
\hline 4 th & 0.9132 & $(0.8910$ & $0.9355)$ & 0.5058 & $(0.4664$ & $0.5452)$ & 0.3820 & $(0.3416$ & $0.4225)$ & 0.5064 & $(0.4587$ & $0.5541)$ \\
\hline Highest & 0.9080 & $(0.8855$ & $0.9304)$ & 0.5258 & $(0.4865$ & $0.5651)$ & 0.5085 & $(0.4664$ & $0.5507)$ & 0.6270 & $(0.5814$ & $0.6726)$ \\
\hline
\end{tabular}




\section{A.3 Cohort Changes in Wealth Gaps in Education}

\begin{tabular}{|c|c|c|c|c|c|c|c|c|c|c|c|c|}
\hline & \multicolumn{3}{|c|}{ High School Graduation } & \multicolumn{3}{|c|}{ College Attendance } & \multicolumn{3}{|c|}{ Bachelor's Graduation } & \multicolumn{3}{|c|}{ BA $\mid$ Attendance } \\
\hline & Rate & $(95 \%$ & C.I.) & Rate & $(95 \%$ & C.I.) & Rate & $(95 \%$ & C.I.) & Rate & $\left(95^{\circ}\right)$ & C.I.) \\
\hline \multicolumn{13}{|c|}{ Net Worth Quintile } \\
\hline \multicolumn{13}{|c|}{ Cohort born 1970-74 } \\
\hline Lowest & 0.7090 & $(0.6525$ & $0.7654)$ & 0.1848 & $(0.1342$ & $0.2353)$ & 0.0649 & $(0.0342$ & $0.0957)$ & 0.1780 & $(0.0983$ & $0.2577)$ \\
\hline 2nd & 0.7606 & $(0.7054$ & $0.8157)$ & 0.2766 & $(0.2221$ & $0.3310)$ & 0.1616 & $(0.1063$ & $0.2168)$ & 0.3407 & $(0.2444$ & $0.4370)$ \\
\hline $3 \mathrm{rd}$ & 0.8216 & $(0.7756$ & $0.8676)$ & 0.3237 & $(0.2649$ & $0.3826)$ & 0.1951 & $(0.1401$ & $0.2501)$ & 0.3211 & $(0.2365$ & $0.4058)$ \\
\hline 4 th & 0.9147 & $(0.8806$ & $0.9489)$ & 0.4427 & $(0.3850$ & $0.5004)$ & 0.3189 & $(0.2572$ & $0.3807)$ & 0.4339 & $(0.3583$ & $0.5095)$ \\
\hline Highest & 0.9146 & $(0.8796$ & $0.9497)$ & 0.5058 & $(0.4427$ & $0.5689)$ & 0.4597 & $(0.3911$ & $0.5282)$ & 0.5374 & $(0.4663$ & $0.6085)$ \\
\hline \multicolumn{13}{|c|}{ Cohort born 1980-84 } \\
\hline Lowest & 0.7443 & $(0.6904$ & $0.7982)$ & 0.2377 & $(0.1887$ & $0.2868)$ & 0.1115 & $(0.0728$ & $0.1502)$ & 0.2362 & $(0.1643$ & $0.3081)$ \\
\hline 2nd & 0.8036 & $(0.7598$ & $0.8474)$ & 0.3220 & $(0.2704$ & $0.3736)$ & 0.1253 & $(0.0820$ & $0.1687)$ & 0.2434 & $(0.1700$ & $0.3168)$ \\
\hline $3 \mathrm{rd}$ & 0.8917 & $(0.8578$ & $0.9256)$ & 0.4393 & $(0.3820$ & $0.4966)$ & 0.2463 & $(0.1957$ & $0.2970)$ & 0.3851 & $(0.3159$ & $0.4543)$ \\
\hline 4 th & 0.8722 & $(0.8376$ & $0.9069)$ & 0.5300 & $(0.4732$ & $0.5868)$ & 0.4031 & $(0.3418$ & $0.4643)$ & 0.5188 & $(0.4468$ & $0.5907)$ \\
\hline Highest & 0.9082 & $(0.8785$ & $0.9380)$ & 0.5617 & $(0.5039$ & $0.6195)$ & 0.6006 & $(0.5378$ & $0.6634)$ & 0.7285 & $(0.6734$ & $0.7835)$ \\
\hline
\end{tabular}




\section{A.4 Cohort Changes in Controlled Wealth Gaps in Education}

\begin{tabular}{|c|c|c|c|c|c|c|c|c|c|c|c|c|}
\hline & \multirow{2}{*}{\multicolumn{3}{|c|}{$\begin{array}{l}\text { High School Graduation } \\
\text { Rate (95\% C.I. })\end{array}$}} & \multicolumn{3}{|c|}{ College Attendance } & \multicolumn{3}{|c|}{ Bachelor's Degree } & \multicolumn{3}{|c|}{ BA $\mid$ Attendance } \\
\hline & & & & Rate & $(95 \%$ & C.I.) & Rate & $(95 \%$ & C.I.) & Rate & $\left(95^{\circ}\right.$ & C.I.) \\
\hline \multicolumn{13}{|c|}{ Net Worth Quintile } \\
\hline \multicolumn{13}{|c|}{ Cohort born 1970-74 } \\
\hline Lowest & 0.8260 & $(0.7720$ & $0.8799)$ & 0.2965 & $(0.2215$ & $0.3716)$ & 0.1574 & $(0.0929$ & $0.2219)$ & 0.3018 & $(0.1800$ & $0.4237)$ \\
\hline 2nd & 0.8172 & $(0.7677$ & $0.8668)$ & 0.3242 & $(0.2667$ & $0.3818)$ & 0.2221 & $(0.1595$ & $0.2847)$ & 0.4046 & $(0.3076$ & $0.5015)$ \\
\hline $3 \mathrm{rd}$ & 0.8342 & $(0.7894$ & $0.8790)$ & 0.3297 & $(0.2732$ & $0.3862)$ & 0.2005 & $(0.1498$ & $0.2511)$ & 0.3262 & $(0.2467$ & $0.4056)$ \\
\hline 4 th & 0.8935 & $(0.8468$ & $0.9401)$ & 0.3874 & $(0.3328$ & $0.4420)$ & 0.2578 & $(0.2068$ & $0.3087)$ & 0.4112 & $(0.3412$ & $0.4813)$ \\
\hline Highest & 0.8824 & $(0.8231$ & $0.9418)$ & 0.3811 & $(0.3192$ & $0.4430)$ & 0.3024 & $(0.2440$ & $0.3608)$ & 0.4533 & $(0.3784$ & $0.5282)$ \\
\hline \multicolumn{13}{|c|}{ Cohort born 1980-84 } \\
\hline Lowest & 0.8059 & $(0.7532$ & $0.8586)$ & 0.3496 & $(0.2802$ & $0.4191)$ & 0.2778 & $(0.2107$ & $0.3448)$ & 0.4477 & $(0.3534$ & $0.5420)$ \\
\hline 2nd & 0.8078 & $(0.7626$ & $0.8531)$ & 0.3858 & $(0.3291$ & $0.4425)$ & 0.2270 & $(0.1675$ & $0.2865)$ & 0.3482 & $(0.2640$ & $0.4324)$ \\
\hline $3 \mathrm{rd}$ & 0.8788 & $(0.8407$ & $0.9169)$ & 0.4370 & $(0.3843$ & $0.4898)$ & 0.2721 & $(0.2256$ & $0.3186)$ & 0.4242 & $(0.3602$ & $0.4883)$ \\
\hline 4 th & 0.8522 & $(0.8092$ & $0.8951)$ & 0.4566 & $(0.3983$ & $0.5149)$ & 0.3075 & $(0.2563$ & $0.3588)$ & 0.4680 & $(0.4010$ & $0.5350)$ \\
\hline Highest & 0.8832 & $(0.8345$ & $0.9319)$ & 0.4386 & $(0.3765$ & $0.5006)$ & 0.3575 & $(0.3032$ & $0.4119)$ & 0.5556 & $(0.4857$ & $0.6255)$ \\
\hline
\end{tabular}




\section{A.5 Decomposition of Growth in Controlled Wealth Gaps in Education}

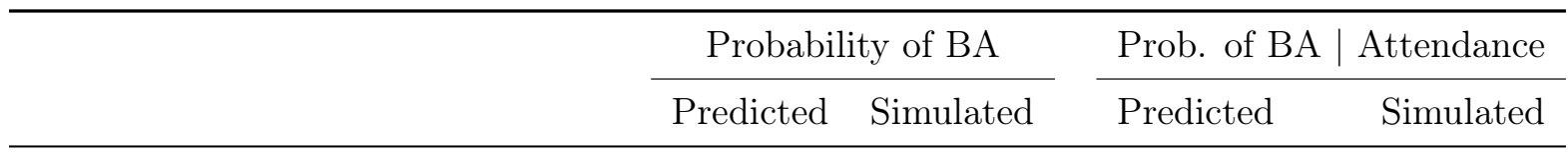

(1) Cohort born in 1970s

$\begin{array}{lll}\text { (1.1) Lowest four wealth quintiles } & 16.0 \% & 31.7 \% \\ \text { (1.2) Highest wealth quintile } & 44.9 \% & 52.9 \% \\ \text { (1.3) Gap [1.2-1.1] } & 28.9 \% & 21.2 \%\end{array}$

2) Cohort born in 1980s

$\begin{array}{lllll}\text { (2.1) Lowest four wealth quintiles } & 18.5 \% & 17.5 \% & 33.4 \% & 32.6 \% \\ \text { (2.2) Highest wealth quintile } & 58.9 \% & 50.4 \% & 71.5 \% & 58.7 \%\end{array}$

(2.2) Highest wealth quintile

$40.4 \%-32.9 \%$

$38.1 \%$

$26.1 \%$

(3) Cohort difference in gap [2.3-1.3] $\quad 11.5 \% \quad 4.0 \% \quad 16.9 \% \quad 4.9 \%$

$\begin{array}{lll}\text { (4) Growth in gap accounted for } & 34.6 \% & 28.7 \%\end{array}$ 


\section{B Appendix: Impacts of the Great Recession}

This appendix discusses how the vast changes in families' wealth during the Great Recession may have contributed to the changing wealth gaps in education presented here. Of course, the potential effect of the Great Recession on inequality in educational outcomes does not alter the description of trends provided here. But understanding whether these trends may be driven by a period effect rather than reflect a broader secular trend is of interest.

I first summarize findings on how the wealth distribution shifted during the last decades and then locate the two birth cohorts studied here within this timeline. I then hypothesize the ways in which the pre- and post-recession period may have impacted the observed trends. Last, I note the results of a stability analysis that partly responds to a measurement concern related to wealth fluctuation around the Great Recession.

\section{The Great Recession and wealth}

Pfeffer and Schoeni (2016) document that wealth inequality has been rising for decades, particularly since the early 2000s and in the run-up to the recession: Relative increases at higher points in the distribution outpaced increases at lower points. Beginning with the crash of the housing market in late 2007, the Great Recession exerted a tremendous and lasting impact on the wealth distribution among U.S. households: Wealth grew even more unequal as lower points in the distribution incurred larger relative losses that were also more sustained through at least 2013. With that, the Great Recession's effects on wealth inequality extended far beyond its official end date of June 2009 (as set by the National Bureau of Economic Research).

Table 5 helps locate the two cohorts studied here in relation to the Great Recession: For the members of cohort 1, born on the 1970s, educational attainment is assessed before the recession. In contrast, substantial macro-economic fluctuation coincided with the educational career of some members of cohort 2, born in the 1980s: They graduated from high school 
and many of them made their college enrollment decision before the recession but some of those who ended up going to college or entertained the decision at a later point did so during the recession.

Table 5: Cohort Timing

\begin{tabular}{lcc}
\hline & Cohort 1 & Cohort 2 \\
\hline \hline Birth year & $1970-1979$ & $1980-1989$ \\
Year turning 18 & $1988-1997$ & $1998-2007$ \\
Year turning 25 & $1994-2004$ & $2005-2014$ \\
\hline
\end{tabular}

\section{Potential effects of the Great Recession on wealth gaps in college outcomes}

Given this timing, the Great Recession's effects should be concentrated on the college outcomes of the second birth cohort, possibly in the following ways:

First, the run-up period to the recession has positively affected their college-going as the emerging housing bubble reduced credit constraints for college access (see Lovenheim 2011). This influx of home equity would have been most consequential for the home-owning middle class whose wealth is chiefly concentrated in their homes, pushing towards a reduction of wealth gaps in college access compared to the earlier cohort. Conversely, the same students who enrolled in college thanks to an influx in home equity were negatively impacted by the bursting of the housing market bubble and ensuing loss of available finances to sustain their further college careers (Johnson 2012), implying that decreasing gaps in college access may not have translated into decreasing gaps in attainment. At the same time, wealthier households were impacted less by the recession since their wealth is typically less concentrated in housing and instead also includes significant financial wealth. After a period of substantial fluctuation, the stock market, however, rebounded much more quickly than the housing market did, translating into less pronounced and less prolonged wealth losses at the top. These trends may have served to preserve the advantage of the wealthiest students in terms of college persistence and attainment. 
Second, as is typical in any recession (Leslie and Brinkman 1987), the Great Recession may have driven more students into college as they avoided weak labor markets (Long 2014), a potential push towards smaller gaps in college access. However, to the extent that students who were only induced to enroll in college by a recession are less prepared for college or less motivated, corresponding increases in persistence and attainment may not follow.

In sum, broad economic forces at work before and during the Great Recession may have helped narrow the wealth gap in college access between the two cohorts studied here while maintaining or even increasing gaps in persistence. This possible direction of influence, of course, is very much in line with the actual trends documented earlier.

\section{Stability analyses}

The tremendous fluctuation in parental wealth before and during the recession may also be considered a measurement challenge (and opportunity for further research) when studying wealth gaps in educational outcomes. For the purpose of the analytical aims pursued here, I engage in a stability analysis that accounts for the fact that the wealth position of children during childhood (age 10-14 as measured here) may differ from that closer to the child's college enrollment decision.

Re-analyses of all presented models of college access and graduation based on wealth measures at age 18 (later ages would introduce endogeneity concerns since college attendance

should be expected to impact family wealth) produce substantively equivalent results (see Online Appendix S.4). As a reminder, wealth measures at age 18 still lie before the Great Recession for all included individuals, so this stability analysis captures wealth fluctuation induced by the run-up to the recession. 


\section{Supplemental Appendix}

"Growing Wealth Gaps in Education" 


\section{Appendix S.1 Sample Attrition}

Here, I describe patterns and potential consequences of sample attrition. In particular, I focus on how the cohorts studied here were affected by the PSID sample reduction in 1997 and assess the sensitivity of the trends described in the paper to the differential impact of this sample reduction.

Table S.1: Sample Structure

\begin{tabular}{|c|c|c|c|c|c|c|c|}
\hline \multirow[b]{2}{*}{ Cohort } & \multirow[b]{2}{*}{ Birth Yr } & \multicolumn{2}{|c|}{ Baseline } & \multicolumn{2}{|c|}{ Outcome (age 20) } & \multicolumn{2}{|c|}{ Outcome (age 25) } \\
\hline & & Age & Survey Yr & Year & Survey Yr & Year & Survey Yr \\
\hline \multirow[t]{10}{*}{$1970 \mathrm{~s}$} & 1970 & 14 & 1984 & 1990 & 1990 & 1995 & 1995 \\
\hline & 1971 & 13 & 1984 & 1991 & 1991 & 1996 & 1996 \\
\hline & 1972 & 12 & 1984 & 1992 & 1992 & 1997 & 1997 \\
\hline & 1973 & 11 & 1984 & 1993 & 1993 & 1998 & 1999 \\
\hline & 1974 & 10 & 1984 & 1994 & 1994 & 1999 & 1999 \\
\hline & 1975 & 14 & 1989 & 1995 & 1995 & 2000 & 2001 \\
\hline & 1976 & 13 & 1989 & 1996 & 1996 & 2001 & 2001 \\
\hline & 1977 & 12 & 1989 & 1997 & 1997 & 2002 & 2003 \\
\hline & 1978 & 11 & 1989 & 1998 & 1999 & 2003 & 2003 \\
\hline & 1979 & 10 & 1989 & 1999 & 1999 & 2004 & 2005 \\
\hline \multirow[t]{10}{*}{$1980 \mathrm{~s}$} & 1980 & 14 & 1994 & 2000 & 2001 & 2005 & 2005 \\
\hline & 1981 & 13 & 1994 & 2001 & 2001 & 2006 & 2007 \\
\hline & 1982 & 12 & 1994 & 2002 & 2003 & 2007 & 2007 \\
\hline & 1983 & 11 & 1994 & 2003 & 2003 & 2008 & 2009 \\
\hline & 1984 & 10 & 1994 & 2004 & 2005 & 2009 & 2009 \\
\hline & 1985 & 14 & 1999 & 2005 & 2005 & 2010 & 2011 \\
\hline & 1986 & 13 & 1999 & 2006 & 2007 & 2011 & 2011 \\
\hline & 1987 & 12 & 1999 & 2007 & 2007 & 2012 & 2013 \\
\hline & 1988 & 11 & 1999 & 2008 & 2009 & 2013 & 2013 \\
\hline & 1989 & 10 & 1999 & 2009 & 2009 & 2014 & 2015 \\
\hline
\end{tabular}

Due to funding shortfalls in the late 1990s, the PSID was forced to reduce its sample by more than 2,000 families between the 1996 and the 1997 survey wave. It did so chiefly by dropping family lineages with low sampling weights, resulting in much more substantial cuts to its initial oversample of low-income African-American families (the Survey of Eco- 
nomic Opportunity, or SEO, sample) than its population-representative sample (the Survey Research Center, or SRC, sample). The two cohorts analyzed here are affected by this drop in different ways, as shown in Table S.1: The great majority of the 1970 birth cohort is unaffected at baseline (when their parental wealth is measured) as well as at the age 20 (when their high school attainment and college entry is assessed). In contrast, the 1980 birth cohort is affected by the sample drop at both measurement points: Educational outcomes at age 20 cannot be observed for any cohort members from families affected by the sample drop (marked in gray) and, in fact, among those born born in the second half of the 1980s, those cases are already lost at baseline (since their parental wealth is measured in 1999, i.e. after the sample drop; marked in dark gray). As a result - and as displayed in Table S.2 - the unweighted attrition rate between baseline and age 20 is slightly higher among the 1980 cohort, largely driven by the higher attrition of the SEO sample through the sample reduction. The attrition pattern is different at age 25, when most of the 1970 cohort is also affected by the sample reduction, reflected in the higher loss of SEO sample members. ${ }^{1}$

Table S.2: Sample Attrition (Unweighted)

\begin{tabular}{|c|c|c|c|c|c|}
\hline & \multicolumn{3}{|c|}{ Analytic sample at } & \multicolumn{2}{|c|}{ Percent of sample lost at } \\
\hline & $\begin{array}{r}\text { Baseline } \\
(1)\end{array}$ & $\begin{array}{r}\text { Age } 20 \\
(2)\end{array}$ & $\begin{array}{r}\text { Age } 25 \\
(3)\end{array}$ & $\begin{array}{r}\text { Age } 20 \\
\text { (2) vs. (1) }\end{array}$ & $\begin{array}{r}\text { Age } 25 \\
\text { (3) vs. (1) }\end{array}$ \\
\hline Born 1970s & 3,283 & 2521 & 1824 & $23.2 \%$ & $44.4 \%$ \\
\hline Main/SRC & 1,617 & 1,345 & 1,163 & $16.8 \%$ & $28.1 \%$ \\
\hline Main/Census & 1,666 & 1,176 & 661 & $29.4 \%$ & $60.3 \%$ \\
\hline Born 1980s & 3,806 & 2832 & 2582 & $25.6 \%$ & $32.2 \%$ \\
\hline Main/SRC & 1,974 & 1,706 & 1,547 & $13.6 \%$ & $21.6 \%$ \\
\hline Main/Census & 1,832 & 1,126 & 1,035 & $38.5 \%$ & $43.5 \%$ \\
\hline
\end{tabular}

\footnotetext{
${ }^{1}$ The attrition rate of the SEO sample between baseline and age 25 among the 1970s cohort appears to not only catch up to but surpass that of the 1980s cohort, which should be understood as a result of the latter already being affected by the sample drop at baseline.
} 
Figure S.1: Trends in Wealth Gaps by Sample
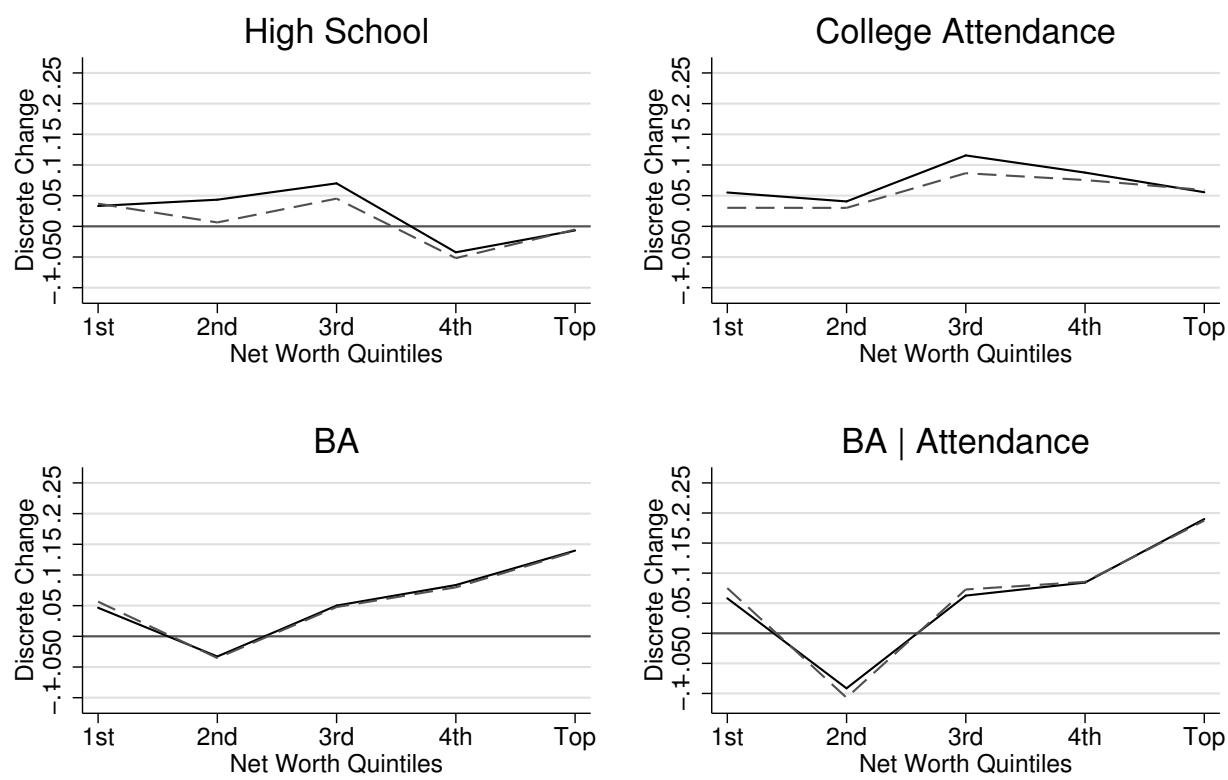

Full Sample - - - - SRC Sample only

In principle, the sampling weights provided by the PSID should compensate for the differential representation of the SEO sample among the two cohorts compared here, much like they do for any other analysis of PSID data that includes the SEO sample. Nevertheless, I also replicate one of the main analyses of this paper - the assessment of cohort trends in education gaps (see Figure 2 in paper) - based on the SRC sample only. Figure S.1 directly compares the trend in the wealth gap for each educational level when based on the full sample (black line) and when based on only the SRC sample (gray dashed line). The differences are negligible for the analysis of educational outcome at age 25 , where, as described above, both cohorts are affected by the 1997 sample reduction. The deviation is higher for the analysis of educational outcomes at age 20, when only the 1980 cohort suffered attrition through the sample reduction. Overall, however, the trends are quite similar and in line with the conclusions based on the full sample (with higher statistical power). 


\section{Appendix S.2 Unweighted Analyses}

Though I recommend against inferential analyses of PSID data without the use of survey weights (including for the reasons described in the preceding section), results from unweighted analyses are presented below. Figure S.2 compares cohort trends derived from weighted regression models (see also Figure 2 in paper) with those derived from unweighted regression models. Figure S.3 compares cohort trends based on quintiles drawn from the weighted distribution (see also Figure 2 in paper) with those based on quintiles drawn from the unweighted distribution. .

Figure S.2: Unweighted Regressions
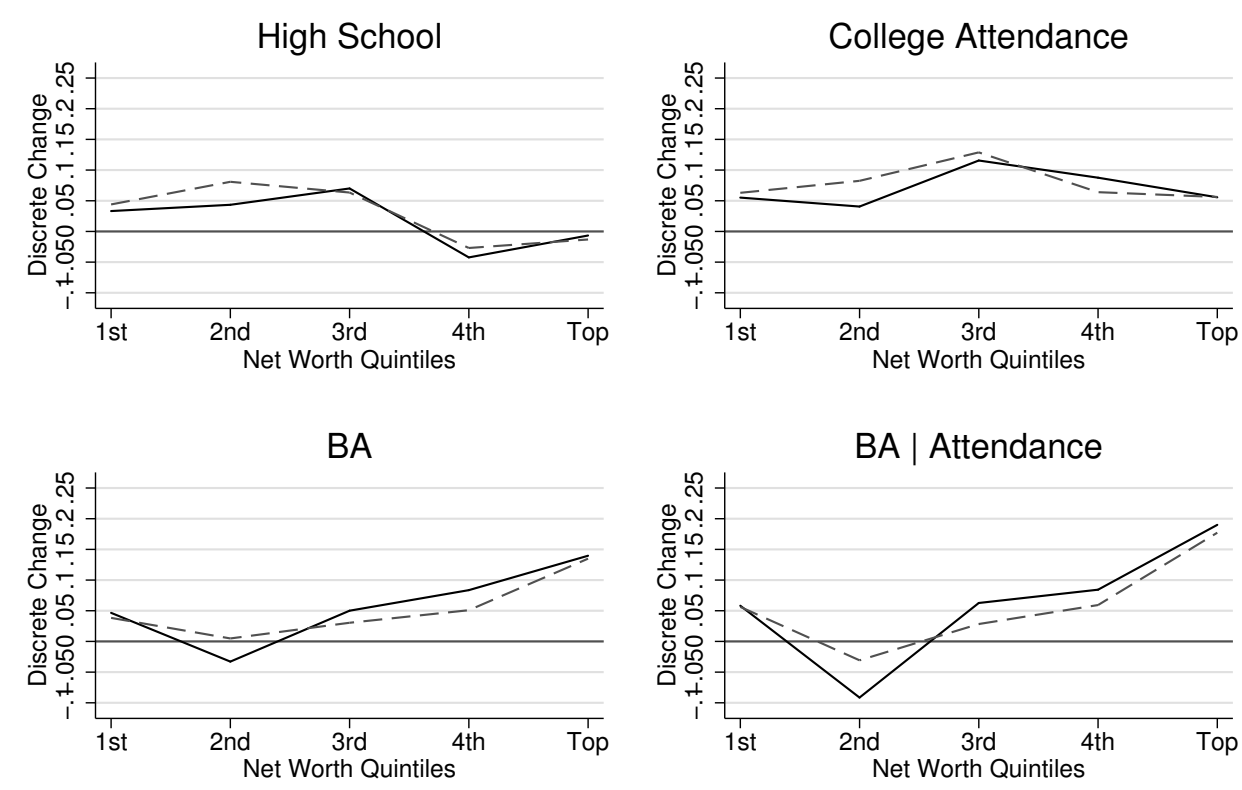

$$
\text { Weighted ----- Unweighted }
$$


Figure S.3: Unweighted Quintiles
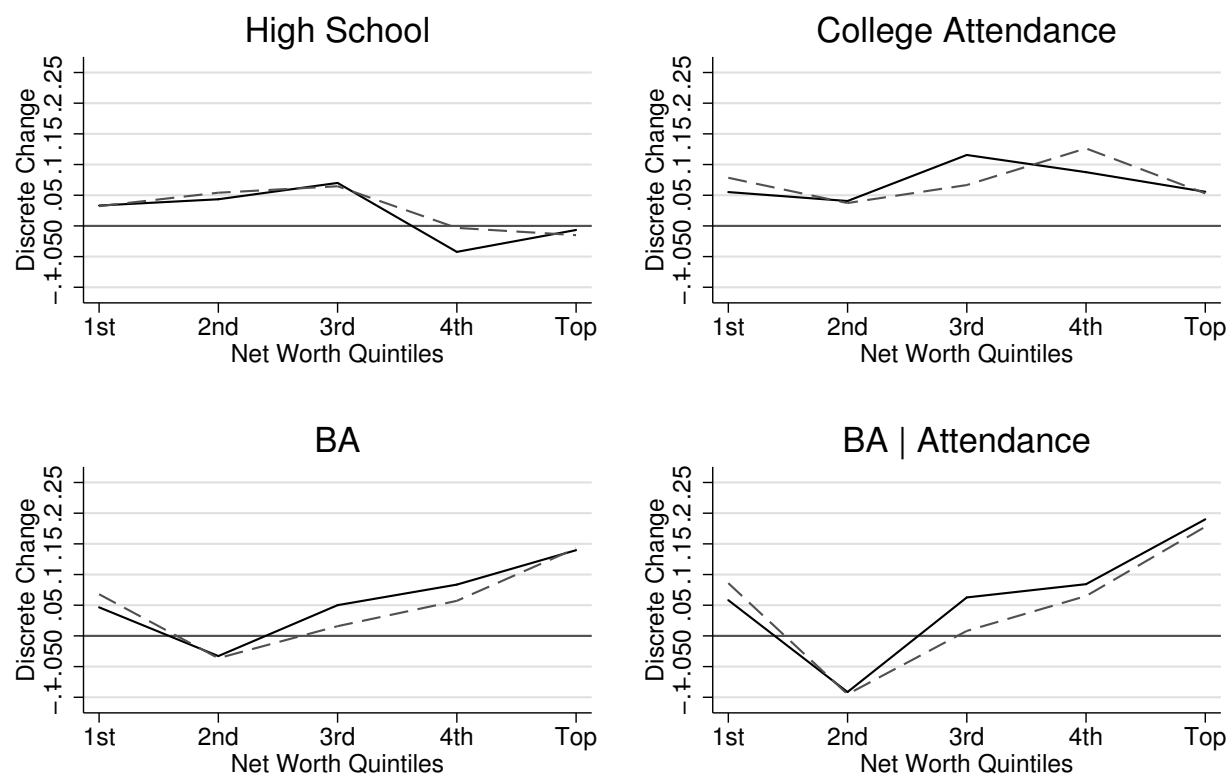

Weighted Quintiles

- - - - Unweighted Quintiles 


\section{Appendix S.3 Linear Probability Models}

Unlike odds ratios or logit coefficients, the use of average marginal effect coefficients circumvents many of the methodological challenges entailed in logistic regression models (e.g. Allison 1999; Mood 2009). Still, the relative benefits of Average Marginal Effects (AME) compared to coefficients from linear probability models (LPM) continue to be debated (e.g. Horrace and Oaxaca 2006; Angrist and Pischke 2008). Here, I report results based on LPMs as a stability analysis. Figure S.4 compares the AME estimates from the logistic regressions with controls (presented in Figure 3 in the paper) to coefficient estimates for LPM models with controls (the two approaches yield equivalent results in uncontrolled models, such as those presented in Figure 2 in the paper).

Figure S.4: Trends in Controlled Wealth Gaps: Logistic Regression vs. LPM
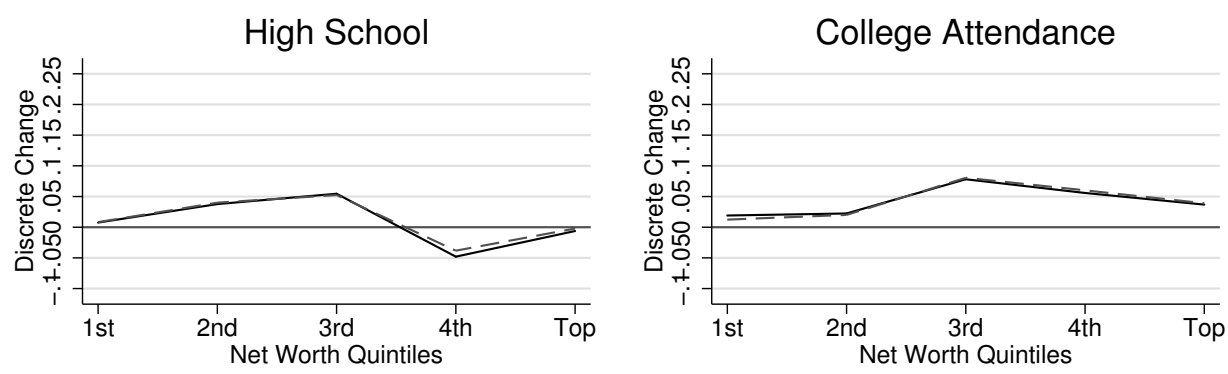

BA
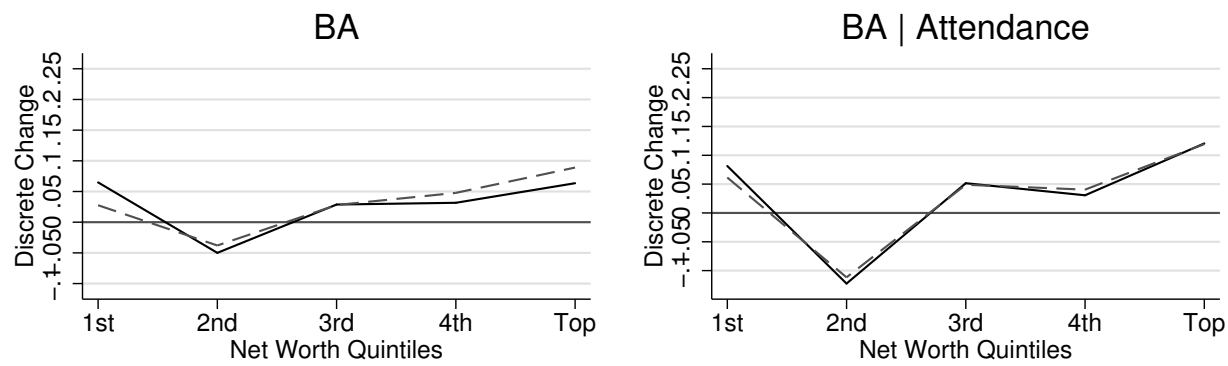

\section{Logistic Model $\quad-----$ Linear Probability Model}

Overall, the differences between the two approaches are negligible. The only deviation in degree but not structure - relates to the growth of the wealth gap in college graduation: Everything else equal, LPM coefficients indicate less progress between the two cohorts among 
those in the bottom quintile of the wealth distribution ${ }^{2}$ and even more progress among those in the top quintile when compared to the cohort trends based on AMEs. The latter thus appear to be conservative estimates of the growing wealth inequality in college attainment.

\footnotetext{
${ }^{2}$ However, it should be noted that the predicted probabilities in the LPM are negative for 13 percent of cases.
} 


\section{Appendix S.4 Measuring Family Wealth at Later Ages}

The main analyses reported in the paper rely on measures of family wealth taken when children are between 10 and 14 years of age. Stability analyses based on measures taken at later ages, 15 to 18 , which may be of particular interest to assess the stability of findings as they relate to wealth fluctuations during the Great Recession (see Appendix B), are reported in Figure S.5. Substantively, conclusions about trends in wealth gaps are unaltered. The only notable deviation between trends based on the two different measurement approaches applies to the college attainment rates among children from the bottom three wealth quintile. While the confidence intervals of the corresponding estimates in the main analyses already covered zero (no change; see Figure 2 in paper), the point estimates based on the later measurement points are also zero, providing an even more uniform picture of lacking progress among the bottom $60 \%$ of the wealth distribution in terms of college graduation and persistence.

Figure S.5: Cohort Trends in Wealth Gaps by Timing of Wealth Measurement
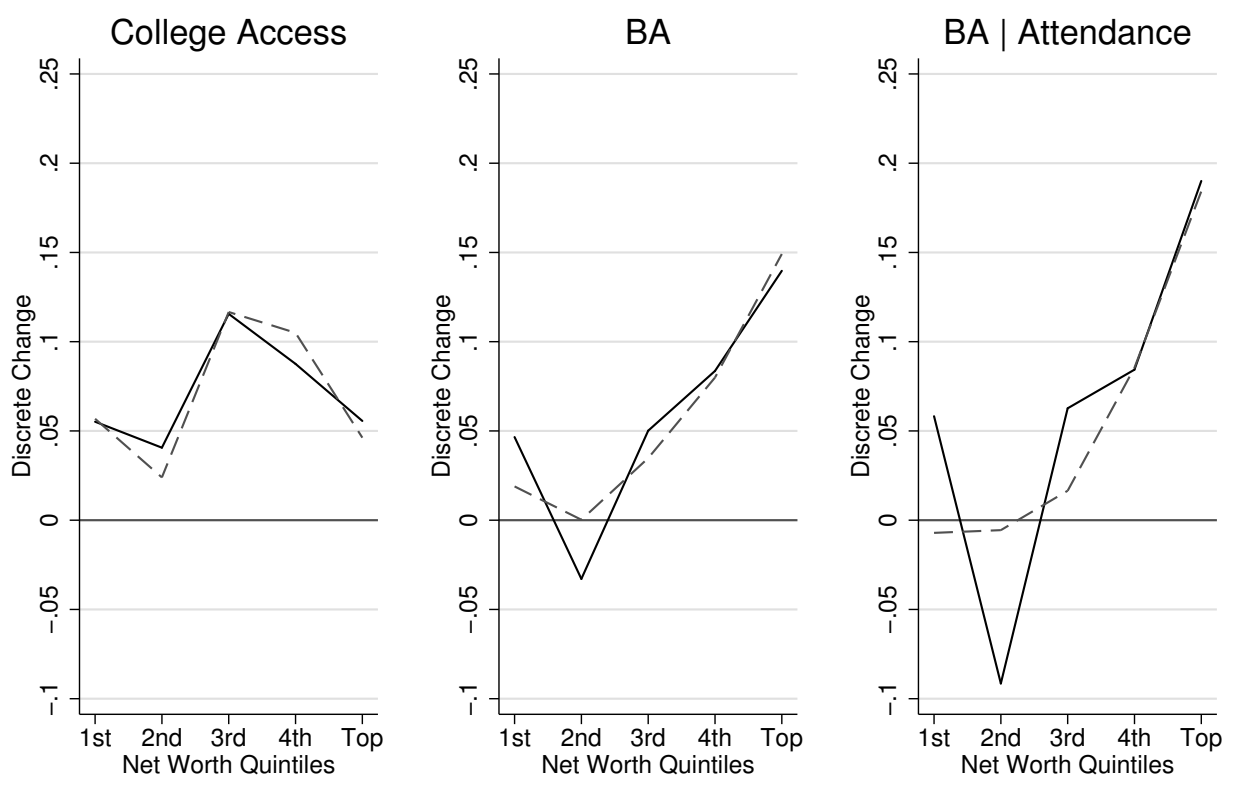

Main Analyses

- - - - Later Measurement 


\section{Appendix S.5 Net Worth Excluding Home Equity}

Table S.3 reports median wealth excluding home equity for three cohorts of children to allow a comparison of wealth inequality trends with and without the inclusion of housing wealth (compare to Table 2 in paper).

Table S.3: Trends in Wealth Inequality Among Children - Excluding Home Equity

\begin{tabular}{|c|c|c|c|}
\hline & \multicolumn{3}{|c|}{ Cohort } \\
\hline & $\begin{array}{r}\text { Earlier } \\
10-14 \text { in } 80 \mathrm{~s}\end{array}$ & $\begin{array}{r}\text { Later } \\
10-14 \text { in } 90 \mathrm{~s}\end{array}$ & $\begin{array}{r}\text { Current } \\
10-14 \text { in } 2015\end{array}$ \\
\hline \multicolumn{4}{|l|}{ Median net worth, excl. home equity } \\
\hline Top 10\% & 520,118 & 681,806 & 840,000 \\
\hline Next $10 \%$ & 175,729 & 212,361 & 244,600 \\
\hline Bottom $80 \%$ & 13,693 & 13,752 & 8,000 \\
\hline \multicolumn{4}{|l|}{ Ratios } \\
\hline Top $10 \% / \operatorname{next} 10 \%$ & 3.0 & 3.2 & 3.4 \\
\hline Top $10 \% /$ bottom $80 \%$ & 38.0 & 49.6 & 105.0 \\
\hline Next $10 \%$ / bottom $80 \%$ & 12.8 & 15.4 & 30.6 \\
\hline Share with zero/neg. net worth excl. home equity & 0.139 & 0.169 & 0.286 \\
\hline Gini coefficient & 0.839 & 0.868 & 0.979 \\
\hline Gini coefficient (positive wealth) & 0.787 & 0.801 & 0.826 \\
\hline
\end{tabular}




\section{Appendix S.6 Decomposition Model}

The decomposition analyses in the paper are geared at further elucidating one particular finding, namely the growth of the gap in college attainment between children from the top quintile and children from the bottom four quintiles of the parental wealth distribution. While off-the-shelf decomposition techniques for non-linear models are available (Fairlie 2005; Sinning et al. 2008), this specific explanatory focus profits from a more flexible approach, such as the spline regression model applied here. The choice of the number and location of spline knots is ultimately arbitrary, so the guiding aim is to closely capture the observed wealth gap in college attainment in the baseline cohort (born in 1970s) while retaining parsimony. As shown in the first two columns of Table S.4 (see also Table 3 in the paper), the spline regression model (1) with two knots at wealth values representing the 80th and 90th percentile of the unweighted distribution ${ }^{3}$ meets that aim very well: deviations between predicted and observed probabilities are negligible or null. Other specifications are less effective in reproducing the observed gaps, including (2) a spline model with just one knot at the 80th percentile, for which the deviation between observed and predicted probabilities are much larger. Predicted probabilities from this model misrepresent the college graduation gap between those from the top quintile of the wealth distribution and everyone else by about five percentage points. A less parsimonious specification using (3) a spline model with knots at the 20th, 40th, 60th, and 80th percentiles does better than that (with deviations between 1 and 2 percentage points) but not as well as the main model (1). The same applies to a specification that (4) separately estimates regressions for the top quintile and the bottom four quintiles.

\footnotetext{
${ }^{3}$ The values representing the same percentiles of the weighted distribution provided a lower fit.
} 
Table S.4: Decomposition: Alternative Predictive Models

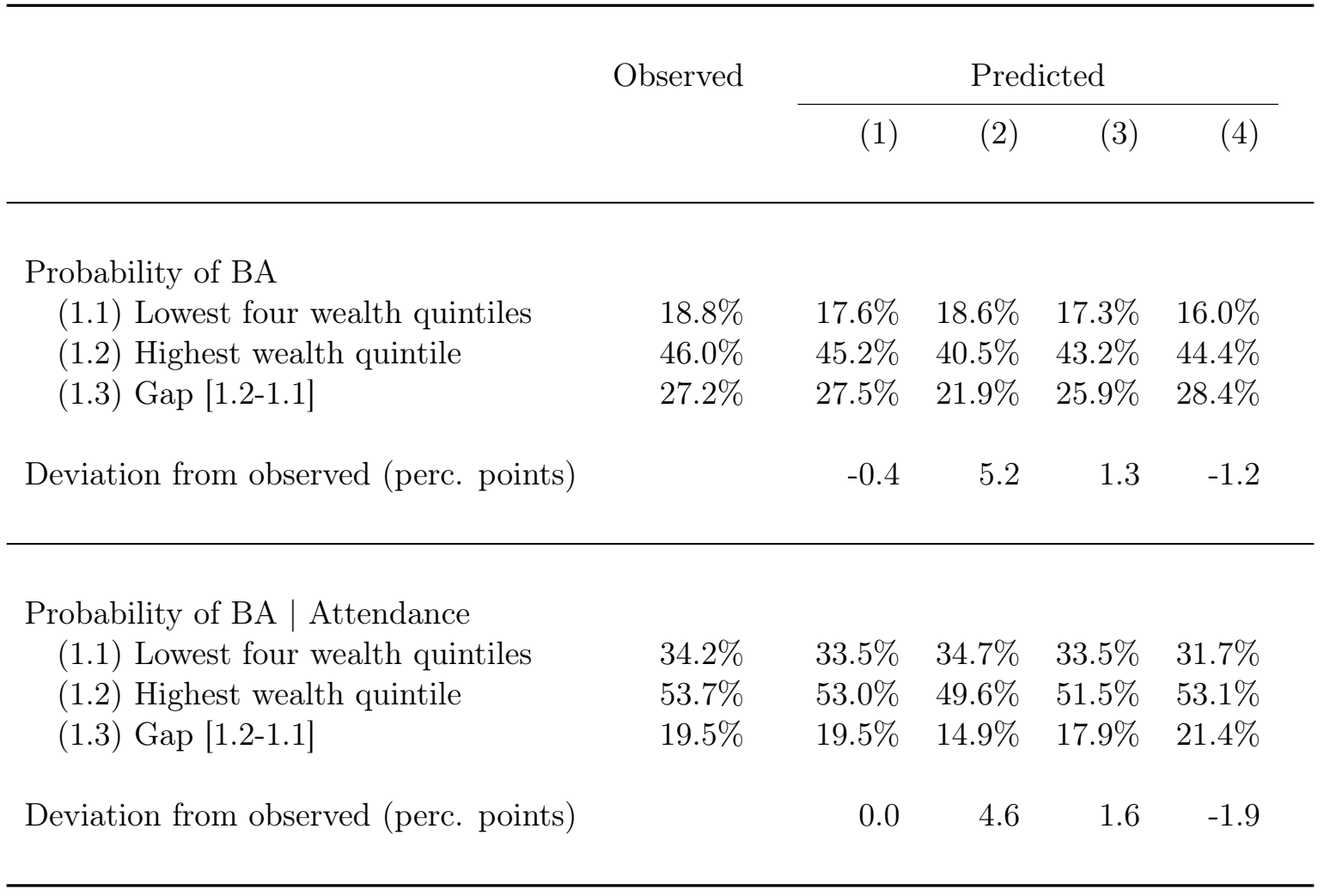

Note: Predictions derived from models specified as:

(1) Splines at P80 and P90 (drawn from full, unweighted sample at age 25) = Main model

(2) Spline at P80 (drawn from full, unweighted sample at age 25)

(3) Splines at quintiles (drawn from full, unweighted sample at age 25)

(4) Separate regressions for highest quintile and bottom four quintiles 


\section{REFERENCES}

Allison, Paul D. 1999. "Comparing Logit and Probit Coefficients Across Groups." Sociological Methods and Research 28:186-208.

Angrist, Joshua D. and Joern-Steffen Pischke. 2008. Mostly Harmless Econometrics. An Empiricist's Companion. Princeton: Princeton University Press.

Fairlie, Robert W. 2005. "An extension of the Blinder-Oaxaca decomposition technique to logit and probit models." Journal of Economic and Social Measurement 30:305-316.

Horrace, William C. and Ronald L. Oaxaca. 2006. "Results on the bias and inconsistency of ordinary least squares for the linear probability model." Economics Letters 90:321-327.

Mood, Carina C. 2009. "Logistic Regression. Why we cannot do what we think we can do, and what we can do about it." European Sociological Review 26:67-82.

Sinning, Mathias, Markus Hahn, Thomas K. Bauer, and others. 2008. "The Blinder-Oaxaca decomposition for nonlinear regression models." The Stata Journal 8:480-492. 